\title{
TOXIC SUBSTANCES FROM COAL COMBUSTION
}

A Comprehensive Assessment

$$
\text { QUARTERLY REPORT }
$$

Reporting Period Start Date: 10/01/1998 End Date: 12/31/1998

$$
\text { Principal Authors: }
$$

CLSenior, T Panagiotou (1) FE Huggins (2), GP Huffman, N Yap (2) JOL Wendt, W Seames (3), MR Ames(4) AF Sarofim, J Lighty (5), A Kolker, R Finkelman, CA Palmer (6),SJ

Mroczkowsky (6) JJ Helble, R. Mamani-Paco (7)

Report Issue Date: 01/28/1999

DE-AC22-95PC95101--12

(1) Physical Sciences Inc.

20 New England Business Center

Andover, MA 01810-1077

(2) University of Kentucky

Lexington, KY 40506-0059

(3) University of Arizona

Tucson, AZ 85721

(4) Massachusetts Institute of Technology

Cambridge, MA 02139

(5) University of Utah

Salt Lake City, UT 84112

(6) U.S. Geological Survey

Reston, VA 20192

(7) University of Connecticut

Storrs, CT 06269 


\section{TABLE OF CONTENTS}

$\underline{\text { Section }} \quad \underline{\text { Page }}$

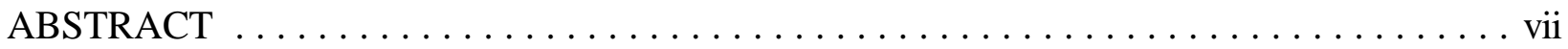

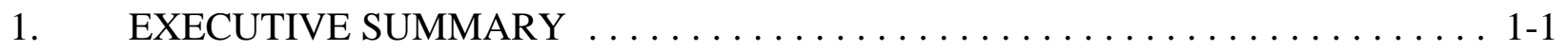

2. INTRODUCTION AND PROGRAM OVERVIEW $\ldots \ldots \ldots \ldots \ldots \ldots \ldots \ldots$.

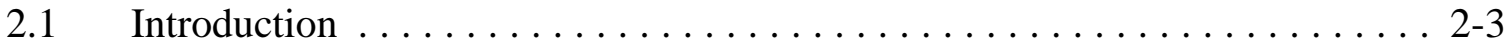

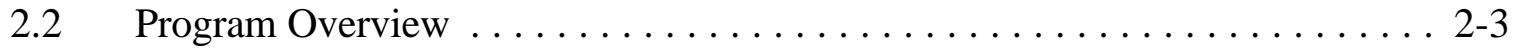

3. RESULTS AND DISCUSSION $\ldots \ldots \ldots \ldots \ldots \ldots \ldots \ldots \ldots \ldots \ldots \ldots \ldots \ldots$

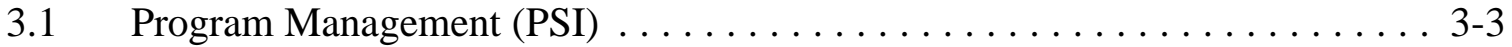

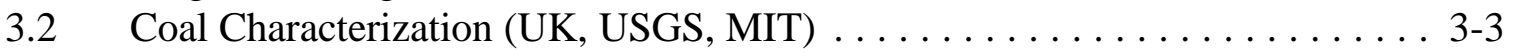

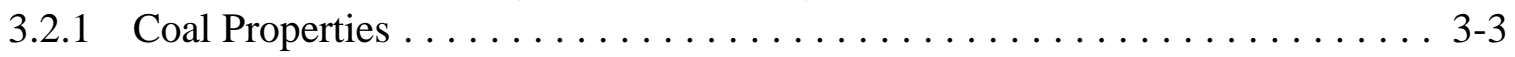

3.2 .2 Coal Mineralogy . . . . . . . . . . . . . . . . . . . . 3-4

3.2.3 Forms of Occurrence of Trace Elements by Microprobe and

Leaching Analysis . . . . . . . . . . . . . . . . . . . . 3-4

3.2.4 Forms of Occurrence of Trace Elements by XAFS . . . . . . . . . . . 3-9

3.3 Combustion Zone Transformations (UU, MIT) . . . . . . . . . . . . 3-10

3.3.1 Metal Vaporization at Devolatization Temperature . . . . . . . . . . . . . . 3-10

3.3.2 Transfer of the MIT Oxidation Drop Tube Furnace to the University of Utah . . . . . . . . . . . . . . . . . . . 3-10

3.3.3 Measurement of Gas-Phase Mercury and Other Trace Metals . . . . . . . . 3 3-11

3.4 Post-Combustion Transformations (UA, UC, UU) . . . . . . . . . . . 3-13

3.4.1 Large Scale Integrated Combustion Studies . . . . . . . . . . . . . . . . 3-13

3.4.2 Measurement of Post-Combustion Chlorine Speciation . . . . . . . . . . . . 3-17

3.4.3 Modeling of Mercury and Chlorine Kinetics . . . . . . . . . . . . . . 3-17

3.4.4 XAFS Study of Mercury in Sorbents . . . . . . . . . . . . . . . 3-27

4. SUMMARY AND FUTURE PLANS $\ldots \ldots \ldots \ldots \ldots \ldots \ldots \ldots \ldots \ldots$

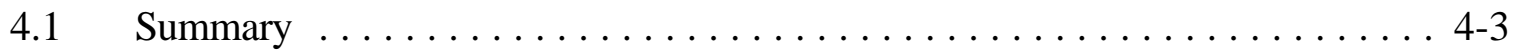

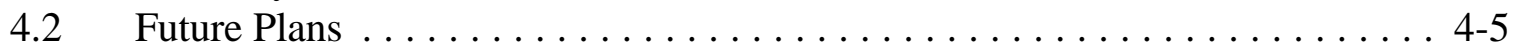

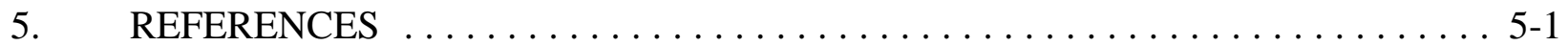

APPENDIX A - Pyrite Analyses from SEM $\ldots \ldots \ldots \ldots \ldots \ldots \ldots \ldots \ldots \ldots \ldots$ 


\section{LIST OF FIGURES}

Figure No.

$\underline{\text { Page }}$

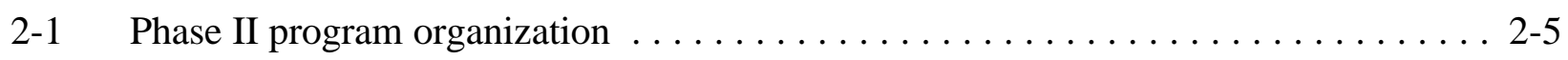

3-1 Plot of arsenic weight percent versus maximum dimension of analyzed pyrite grains in the three Phase II coals . . . . . . . . . . . . . . . 3-7

3-2 Plot of arsenic versus nickel in Phase II pyrites $\ldots \ldots \ldots \ldots \ldots \ldots \ldots$

3-3 Plot of arsenic versus lead in Phase II pyrite grains $\ldots \ldots \ldots \ldots \ldots \ldots \ldots \ldots$

3-4 Selenium XANES spectrum of Ohio bituminous coal and tailings fraction

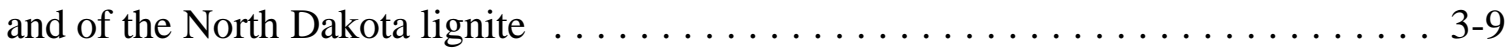

3-5 Oxidation Drop Tube Furnace at the University of Utah $\ldots \ldots \ldots \ldots$. . . . 3-12

3-6 Schematic of the Oxidation Drop Tube Furnace. . . . . . . . . . . . . . . 3-12

3-7 Typical naturally evolving temperature profile from Ohio baseline experiments . . . . 3-16

3-8 Typical particle size distributions for Ohio baseline experiments $\ldots \ldots \ldots \ldots \ldots$. . . . .

3-9 Expanded view of submicron particle size distributions for Ohio baseline experiments. . . . . . . . . . . . .

3-10 Concentration of $\mathrm{Cl}_{2}$ in flue gas as a function of temperature for different

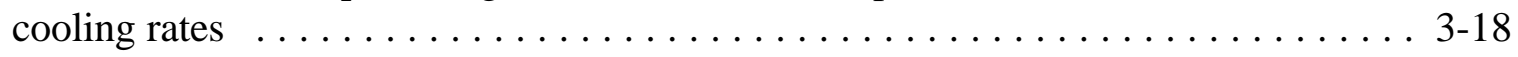

3-11 Concentration of $\mathrm{Cl}$ in flue gas as a function of temperature for different cooling rates. .......................... 3-19

3-12 Rate constant of Reaction (6) as a function of temperature from $273 \mathrm{~K}$ to $973 \mathrm{~K}$. . . 3-21

3-13 $\mathrm{Hg}$ conversion as a function of $\mathrm{HCl}$ concentration at $773 \mathrm{~K}$ using global kinetics . . . 3-23

3-14 $\mathrm{Hg}$ conversion as a function of $\mathrm{HCl}$ concentration at $973 \mathrm{~K}$ using global kinetics . . . 3-23

3-15 $\mathrm{Hg}$ conversion as a function of $\mathrm{Cl}_{2}$ concentration at $773 \mathrm{~K}$ using global kinetics . . . 3-24

3-16 $\mathrm{Hg}$ conversion as a function of $\mathrm{Cl}_{2}$ concentration at $973 \mathrm{~K}$ using global kinetics . . . 3-24

3-17 Hg conversion for two different cooling rate using global kinetics. . . . . . . . 3-25 


\section{LIST OF FIGURES (Continued)}

Figure No. $\quad \underline{\text { Page }}$

3-18 Fraction of elemental mercury converted for two different cooling rates

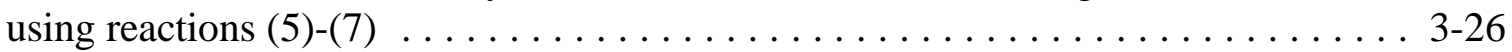

3-19 $\mathrm{Hg}$ conversion as a function of $\mathrm{Cl}$ atom concentration at $773 \mathrm{~K}$ and

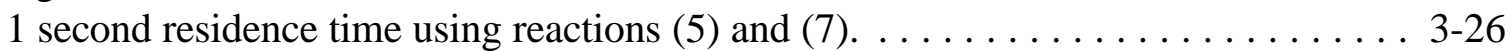

3-20 Simulated XANES spectra and derivative spectra for mercuric chloride

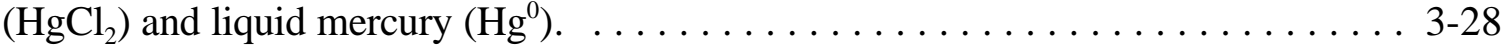

3-21 Plot of the Inflection Point Difference (IPD) against the peak-height ratio determined from the derivative spectra shown in Figure $3-20 \ldots \ldots \ldots \ldots$. . . . . . . 


\section{LIST OF TABLES}

Table No.

Page

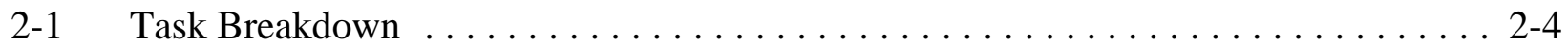

3-1 Summary of Coal Characteristics for Phase II Coals $\ldots \ldots \ldots \ldots \ldots \ldots \ldots \ldots \ldots$

3-2 Preliminary Mineralogy - Phase II Coals (SEM Only) $\ldots \ldots \ldots \ldots \ldots \ldots \ldots \ldots . . \ldots \ldots$

3-3 Preliminary Leaching Data, INAA Only (Hg by CVAA) $\ldots \ldots \ldots \ldots \ldots \ldots \ldots$ 3-6

3-4 Summary of the Phase II Ohio Baseline Test Runs ................... 3-9

3-5 Summary of Experimental Sampling Conditions $\ldots \ldots \ldots \ldots \ldots \ldots \ldots \ldots \ldots \ldots \ldots \ldots \ldots$

3-6 Initial Conditions Used in Global Kinetic Mercury Conversion

Rate Calculations .............................. 3-12 


\begin{abstract}
The Clean Air Act Amendments of 1990 identify a number of hazardous air pollutants (HAPs) as candidates for regulation. Should regulations be imposed on HAP emissions from coal-fired power plants, a sound understanding of the fundamental principles controlling the formation and partitioning of toxic species during coal combustion will be needed. With support from the Federal Energy Technology Center (FETC), the Electric Power Research Institute, and VTT (Finland), Physical Sciences Inc. (PSI) has teamed with researchers from USGS, MIT, the University of Arizona (UA), the University of Kentucky (UK), the University of Connecticut (UC), the University of Utah (UU) and the University of North Dakota Energy and Environmental Research Center (EERC) to develop a broadly applicable emissions model useful to regulators and utility planners. The new Toxics Partitioning Engineering Model (ToPEM) will be applicable to all combustion conditions including new fuels and coal blends, low- $\mathrm{NO}_{\mathrm{x}}$ combustion systems, and new power generation plants. Development of ToPEM will be based on PSI's existing Engineering Model for Ash Formation (EMAF).
\end{abstract}

This report covers the reporting period from 1 October 1998 to 31 December 1998. During this period basic coal testing at USGS was completed. Preliminary mineralogy of the three Phase II coals was determined by SEM/EDX. Selective leaching procedures for the Ohio and North Dakota samples have been completed, and a portion (INAA and ICP-AES acid digest) of the analytical results have been returned. The Wyodak sample was received after these two samples, and is currently in the final stage of the leaching procedure. The $\mathrm{HNO}_{3}$ leaching data appears to be in error, probably due to a problem with the normality of the acid and this leaching step will be re-done. Electron microprobe analyses were obtained for a number of pyrite grains in each of the three Phase II coals. Elements determined include $\mathrm{Pb}, \mathrm{Se}, \mathrm{Cu}, \mathrm{Cd}, \mathrm{As}, \mathrm{Ni}, \mathrm{Zn}, \mathrm{Co}, \mathrm{Fe}$, and S. Cold vapor atomic fluorescence (CVAF) development work for $\mathrm{Hg}$ analyses is ongoing at USGS. Analysis of Se XAFS data obtained at NSLS in July 1998 for the Ohio and North Dakota coals was attempted during the quarter by the University of Kentucky. The Se XANES spectra for the Ohio coal appear to indicate a significant Se/pyrite association. The University of Utah has begun work to determine whether metals are vaporized at the low temperatures typical of the devolatization stage of pulverized coal combustion. The Oxidation Drop Tube Furnace previously at MIT was transferred to the Combustion Research Laboratory of the University of Utah. MIT has re-tested its iodated charcoal sorbent traps for the collection of $\mathrm{Hg}^{0}$ and $\mathrm{HgCl}_{2}$ and the $100 \mathrm{mg}$ traps were verified to be $100 \%$ efficient for total $\mathrm{Hg}$ collection. A reliable analysis of sampled $\mathrm{Hg}$ requires that at least a few nanograms of $\mathrm{Hg}$ be collected. This should be readily attainable in even the very small combustors/reactors. Progress has been made in the development of a dry system for the separate collection of $\mathrm{HgCl}_{2}$ and $\mathrm{Hg}^{0}$. The University of Arizona's pilot-scale downflow laboratory combustion furnace was used to test the partitioning of toxic metals in the Phase II baseline experiments for the Ohio coal. These analyses are still in progress and the results will be reported in the next quarterly report for January through March 1999. Measurement of chlorine speciation in post-combustion flue gas will be made at the University of Utah U-furnace using EPA Method 26A. Work has started on designing an experimental series tentatively consisting of three different gas cooling rates. This quarter we began consideration of the kinetics of mercury oxidation by chlorine. To investigate the importance of reaction kinetics in determining the extent of mercury oxidation, the University of 
Connecticut conducted kinetic calculations of mercury oxidation under conditions relevant to pulverized coal combustion. Two different kinetic models were considered. Global kinetics from the literature were used to examine overall mercury oxidation. For a cooling rate of $-200 \mathrm{~K} \mathrm{~s}^{-1}$, an overall conversion of $24 \%$ is achieved in 2 seconds which is consistent with measurements of gas-phase $\mathrm{Hg}^{+2}$ in coal-fired power plant flue gas. To assess the importance of atomic $\mathrm{Cl}$, further kinetic calculations were conducted using elementary reactions. Mercury conversions of comparable magnitude to the field data were obtained at atomic $\mathrm{Cl}$ concentrations of one hundred-fold less than those suggested by the major constituent gas phase reaction chemistry. This suggests that accurate prediction of mercury speciation in coal combustion systems using a mechanistic model will require detailed knowledge of the super-equilibrium chlorine atom concentrations. Data analysis of XANES spectra obtained for mercury sorbed on coal chars prepared at the University of Arizona and on similar samples prepared in other experimental projects outside of the project continued this quarter at the University of Kentucky. The usefulness of the Inflection Point Difference (IPD), defined as the separation in $\mathrm{eV}$ of the peaks in the first derivative of the Hg XANES spectrum, was established. This parameter is a simple but effective probe of the nearest neighbor ligands that surround the mercury atoms sorbed on carbon-based sorbents. The combination of the IPD parameter and the derivative peak-height ratio appears to have the potential to discriminate between chemisorption and physisorption of mercury. 


\section{SECTION 1}

EXECUTIVE SUMMARY

$1-1 / 1-2$ 


\section{EXECUTIVE SUMMARY}

The technical objectives of this project are:

a) To identify the effect of the mode-of-occurrence of toxic elements in coal on the partitioning of these elements among vapor, submicron fume, and fly ash during the combustion of pulverized coal,

b) To identify the mechanisms governing the post-vaporization interaction of toxic elements and major minerals or unburnt char,

c) To determine the effect of combustion environment (i.e., fuel rich or fuel lean) on the partitioning of trace elements among vapor, submicron fume, and fly ash during the combustion of pulverized coal,

d) To model the partitioning of toxic elements among various chemical species in the vapor phase and between the vapor phase and complex aluminosilicate melts,

e) To develop the new Toxics Partitioning Engineering Model (ToPEM), applicable to all combustion conditions including new fuels and coal blends, low- $\mathrm{NO}_{\mathrm{x}}$ combustion systems, and new power generation plants.

A description of the work plan for accomplishing these objectives is presented in Section 2.1 of this report.

The work discussed in this report covers the reporting period from 1 October 1998 to 31 December 1998. During this quarter, basic coal testing at USGS was completed. Total sulfur contents range from $0.43 \mathrm{wt} \%$ in the Wyodak to $2.68 \mathrm{wt} \%$ in the Ohio sample. In the North Dakota and Ohio samples, about half of the total sulfur is pyritic and half is organic. The North Dakota sample also contains a minor amount of sulfate, consistent with the presence of barite in this sample. In the Wyodak sample, the majority of the sulfur is organic. Preliminary mineralogy of the three Phase II coals was determined by SEM/EDX. The Ohio coal contains all of the five most common major phases: quartz, illitic clay, kaolinitic clay, pyrite and calcite. Based on this preliminary work, the North Dakota sample appears to lack both kaolinite and calcite, and the Wyodak sample appears to lack calcite. Subsequent SEM work will attempt to reconfirm the basic findings presented here, and identify additional trace phases that could host the elements of interest in this study.

At the present time, selective leaching procedures for the Ohio and North Dakota samples have been completed, and a portion (INAA and ICP-AES acid digest) of the analytical results have been returned. The Wyodak sample was received after these two samples, and is currently in the final stage of the leaching procedure. Preliminary leaching results for the Ohio and North Dakota samples are reported, based only on INAA and CVAA ( $\mathrm{Hg}$ ) results on the bulk starting material and the solid residues after each leaching step. Final values for percentages leached and 
the trace-element composition of the starting coals will be reported when all of the analyses are available. The $\mathrm{HNO}_{3}$ leaching data appears to be in error, probably due to a problem with the normality of the acid. Work will continue to re-do this step.

Electron microprobe analyses were obtained for a number of pyrite grains in each of the three Phase II coals. Elements determined include $\mathrm{Pb}, \mathrm{Se}, \mathrm{Cu}, \mathrm{Cd}, \mathrm{As}, \mathrm{Ni}, \mathrm{Zn}, \mathrm{Co}, \mathrm{Fe}$, and $\mathrm{S}$. Analytical methods are similar to those used in Phase I, except that $\mathrm{Pb}$ has been added to the procedure. The data are not sufficient to make generalizations about trace-element differences among the various forms, or to approximate average concentrations of these elements in pyrite for each sample.

Cold vapor atomic fluorescence (CVAF) development work for $\mathrm{Hg}$ analyses is ongoing at USGS. Trials indicate that the minimum detection limit by this method is limited by a total analytical blank level in the 0.01 to $0.02 \mathrm{ppm}$ (10 to $20 \mathrm{ppb}$ ) range, similar to the detection limit for the previous (CVAA) method. As an interim step, $\mathrm{Hg}$ analyses will be done by CVAA, in parallel with CVAF development. Once an acceptable CVAF blank level is attained, the analyses will be repeated as necessary.

Analysis of Se XAFS data obtained at NSLS in July 1998 for the Ohio and North Dakota coals was attempted during the quarter by the University of Kentucky. But the data were poor with relatively high noise, reflecting the fact that both coals contain only about $1.5 \mathrm{ppm}$ Se and the data collection was not long enough, especially for the North Dakota lignite. Despite the relatively poor quality of the data, the Se XANES spectra for the Ohio coal do appear to indicate a significant Se/pyrite association. New Se XAFS data will be collected for all project coals during our next synchrotron session at SSRL in February 1999.

The University of Utah has begun work to determine whether metals are vaporized at the low temperatures typical of the devolatization stage of pulverized coal combustion. The heating conditions selected were those used for an ASTM volatiles determination. Duplicate samples of both the parent coal and the fixed carbon were prepared for seven coals. These samples have been sent to MIT for elemental analysis by neutron activation.

The Oxidation Drop Tube Furnace previously at MIT was transferred to the Combustion Research Laboratory of the University of Utah. The transfer process involved the design of a semi-closed cooling system as well as the reconstruction of the gas and particle feeding units and of the particle and gas collecting facilities.

MIT has re-tested its iodated charcoal sorbent traps for the collection of $\mathrm{Hg}^{0}$ and $\mathrm{HgCl}_{2}$. The $100 \mathrm{mg}$ traps were verified to be $100 \%$ efficient for total $\mathrm{Hg}$ collection at a gas flow rate of 1 liter per minute. The $\mathrm{Hg}$ blank level in these traps is 1 nanogram. Therefore a reliable analysis of sampled $\mathrm{Hg}$ requires that at least a few nanograms of $\mathrm{Hg}$ be collected. This requirement for a few nanograms of collected $\mathrm{Hg}$ should be readily attainable in even the very small combustors/reactors. Progress has been made in the development of a dry system for the separate collection of $\mathrm{HgCl}_{2}$ and $\mathrm{Hg}^{0}$ which should be simpler to use than the Ontario Hydro 
impinger method and which will use a collection medium for $\mathrm{HgCl}_{2}$ suitable for analysis by neutron activation.

The University of Arizona's pilot-scale downflow laboratory combustion furnace was used to test the partitioning of toxic metals in the Phase II baseline experiments for the Ohio coal. A total of 16 sets of particulate samples were collected during nine test runs under baseline combustion conditions. One representative sample set from Port 4 and the corresponding sample set from Port 14 were selected for analysis of size-segregated particle metal content at MIT by NAA. Two representative sample sets from Port 4 and the corresponding sample sets from Port 14 plus one sample set from the baghouse inlet were selected for analysis of size-segregated particle metal content at the University of Arizona by AA/GFAA. These analyses are still in progress and the results will be reported in the next quarterly report.

Measurement of chlorine speciation in post-combustion flue gas will be made at the University of Utah U-furnace using EPA Method 26A. The sample train for chlorine and $\mathrm{HCl}$ sampling has been assembled but a few parts are still missing. Work has started on designing an experimental series tentatively consisting of three different gas cooling rates.

Chlorine-containing species have been shown to be the most important for oxidation of elemental mercury in flue gas. Other flue gas constituents have relatively minor effects. Understanding the speciation of mercury in full-scale combustion systems must therefore take into consideration the kinetics of mercury and chlorine species in flue gas. This quarter we began consideration of the kinetics of mercury oxidation by chlorine. To investigate the importance of reaction kinetics in determining the extent of mercury oxidation, the University of Connecticut conducted kinetic calculations of mercury oxidation under conditions relevant to pulverized coal combustion. Two different kinetic models were considered. Global kinetics from the literature were used to examine overall mercury oxidation under a range of conditions. Under isothermal conditions, a greater sensitivity to changes in $\mathrm{Cl}_{2}$ concentration as compared to $\mathrm{HCl}$ was observed. Calculations using the combined global reactions were also conducted at cooling rates that are typical of coal-fired power plants. Mercury conversion is higher at the slower cooling rate, a result of increased residence time at higher temperatures. For the cooling rate of $-200 \mathrm{~K} \mathrm{~s}^{-1}$, an overall conversion of $24 \%$ is achieved in 2 seconds which is consistent with measurements of gas-phase $\mathrm{Hg}^{+2}$ in coal-fired power plant flue gas.

To assess the importance of atomic $\mathrm{Cl}$, further kinetic calculations were conducted using elementary reactions. Use of this reaction set was seen to result in complete conversion of elemental mercury within 1 second. Order of magnitude reductions in the atomic $\mathrm{Cl}$ concentration significantly reduced the conversion, however. Mercury conversions of comparable magnitude to the field data were obtained at atomic $\mathrm{Cl}$ concentrations of one hundred-fold less than those suggested by the major constituent gas phase reaction chemistry. This suggests that accurate prediction of mercury speciation in coal combustion systems using a mechanistic model will require detailed knowledge of the super-equilibrium chlorine atom concentrations. 
The usefulness of the parameter derived from the mercury $\mathrm{L}_{\mathrm{III}}$-edge XANES spectra, namely the Inflection Point Difference (IPD), defined as the separation in eV of the peaks in the first derivative of the $\mathrm{Hg}$ XANES spectrum, was established. This parameter is a simple but effective probe of the nearest neighbor ligands that surround the mercury atoms sorbed on carbon-based sorbents. In the current quarter, we have explored one possible reason for this variation in terms of a mixture of chemisorption, involving formation of a $\mathrm{HgCl}_{2}$ or $\mathrm{HgS}$ species on the char surface, and physisorption of elemental mercury. This was done by simulation of a suite of Hg XANES spectra from end-member standard spectra for metallic (liquid) mercury and either mercuric chloride or mercuric sulfide. The combination of the IPD parameter and the derivative peak-height ratio appears to have the potential to discriminate between chemisorption and physisorption. 


\section{SECTION 2}

INTRODUCTION AND PROGRAM OVERVIEW 


\section{INTRODUCTION AND PROGRAM OVERVIEW}

\section{$2.1 \quad$ Introduction}

Before electric utilities can plan or implement emissions minimization strategies for hazardous pollutants, they must have an accurate and site-specific means of predicting emissions in all effluent streams for the broad range of fuels and operating conditions commonly utilized. Development of a broadly applicable emissions model useful to utility planners first requires a sound understanding of the fundamental principles controlling the formation and partitioning of toxic species during coal combustion. PSI and its team members will achieve this objective through the development of an "Engineering Model" that accurately predicts the formation and partitioning of toxic species as a result of coal combustion. The "Toxics Partitioning Engineering Model" (ToPEM) will be applicable to all conditions including new fuels or blends, low- $\mathrm{NO}_{\mathrm{x}}$ combustion systems, and new power systems being advanced by DOE in the Combustion 2000 program.

Based on a goal of developing and delivering this ToPEM model, a 5-year research program was proposed. This program is divided into a 2-year Phase I program and a 3-year Phase II program. The objective of the ongoing Phase II program is to develop an experimental and conceptual framework for the behavior of selected trace elements (arsenic, selenium, chromium, and mercury) in combustion systems and incorporate these concepts into a new engineering model. This Phase II objective will be achieved by a team of researchers from USGS, the Massachusetts Institute of Technology (MIT), the University of Arizona (UA), the University of Kentucky (UK), the University of Connecticut (UC), the University of Utah (UU), the University of North Dakota Energy \& Environmental Research Center (EERC) and PSI. Model development and commercialization will be carried out by PSI.

\subsection{Program Overview}

Our general approach to the development of the ToPEM model is to break the process for toxic formation into sub-processes, each of which will be addressed by team members who are experts in the area. Ultimately, this will result in new sub-models which will be added to the existing Engineering Model for Ash Formation (EMAF) to create ToPEM. Table 2-1 describes the work breakdown structure for the Phase II program. Figure 2-1 illustrates the relationship between the elements of the Phase I work breakdown structure and the subprocesses. Each of the areas identified in the figure will be addressed in the Phase II program as described below.

\section{Forms of Occurrence of Trace Elements in Coal}

One of the most important questions to be answered in the program as a whole is whether the form of a particular element in the coal affects its form of emission at the end of the process. The answer to this question will determine the shape of the sub-models that must be developed in this program. Thus, a detailed understanding of the forms of individual trace elements in coal 
Table 2-1. Task Breakdown

\begin{tabular}{|l|c|c|}
\hline \multicolumn{1}{|c|}{ Technical Task } & $\begin{array}{c}\text { Team } \\
\text { Member }\end{array}$ & $\begin{array}{c}\text { Task (WBS) } \\
\text { Number }\end{array}$ \\
\hline \hline Program management & PSI & 1 \\
\hline Coal acquisition, characterization & PSI & 2 \\
\hline Coal, ash trace element characterization & PSI & 2 \\
\hline $\begin{array}{l}\text { Coal (and ash) characterization -- forms of } \\
\text { occurrence }\end{array}$ & UK, USGS & 3,4 \\
\hline $\begin{array}{l}\text { Coal, ash trace element characterization and } \\
\text { mercury capture and analysis }\end{array}$ & MIT & 5.2 \\
\hline $\begin{array}{l}\text { Mechanistic study: dilute bench scale combustion } \\
\text { tests plus equilibrium, kinetic modeling }\end{array}$ & UU & 5.1 \\
\hline Large scale tests at 100,000 Btu/h facility & UA & 6 \\
\hline $\begin{array}{l}\text { Mechanistic study of kinetic rates for gas-phase } \\
\text { reactions }\end{array}$ & UC & 10 \\
\hline Mercury-fly ash interactions at bench scale & EERC & 11 \\
\hline Fundamental Engineering Model development & PSI & 9.1 \\
\hline $\begin{array}{l}\text { Inorganic emissions: literature survey and model } \\
\text { validation }\end{array}$ & UC & 9.2 \\
\hline
\end{tabular}

provides a foundation for much of the rest of the program. Key issues that will be addressed in Phase II are the specific mineral associations of individual elements and the relationship between trace metal form and "standard" coal analyses.

Because of the importance of elemental form (e.g., sulfate versus silicate mineral) on partitioning, it is critical that coals representing a broad range of elemental forms be examined in this program. In Task 2 we will select and acquire a total of three coals for study in this program. The coals chosen will represent a broad range of elemental forms of occurrence taken from the major coal ranks and commercial coal seams used for pulverized coal power generation in the US. Once selected, fresh coal samples will be acquired and distributed to team members. These samples will be subjected to ultimate, proximate, and ASTM ash analysis. Coal samples will be analyzed for trace element concentrations by Neutron Activation Analysis (NAA) at the MIT Nuclear Reactor Laboratory (Task 5.2).

Advanced analytical techniques such as Mössbauer spectroscopy and ComputerControlled Scanning Electron Microscopy (CCSEM) will be used by UK (Task 3) to determine the major mineral species present in the program coals and the combustion generated ash. Whole coal samples and density segregated coal samples will be studied. This analysis will provide important insight on the minerals present in the coal, how they interact during the combustion process, and how this interaction may affect the partitioning of toxic elements. 


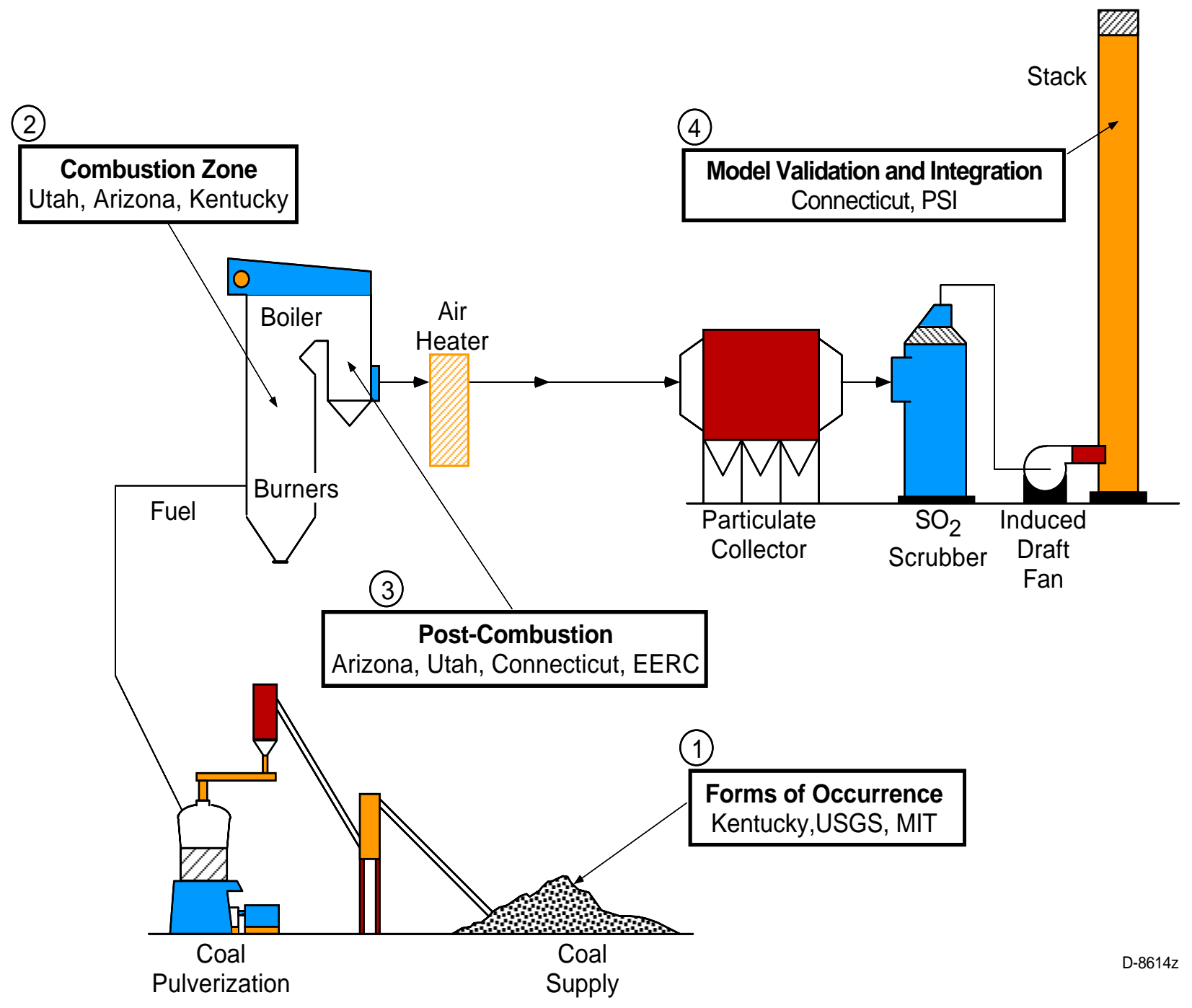

Figure 2-1. Phase II program organization.

Another important issue is the form-of-occurrence of the trace elements in the coal. In this task the mode of occurrence of As, Cr, and Se will be determined by combining XAFS and the Mössbauer/CCSEM derived data discussed above. $\mathrm{Hg}$ will also be evaluated where possible. Other less critical trace elements ( $\mathrm{Mn}, \mathrm{Ni}, \mathrm{Zn}, \mathrm{Pb}, \mathrm{U}$, etc.) may also be evaluated, especially if their abundance is unusually high in any of the program coals. In addition, the form-of-occurrence of $\mathrm{Cl}$ and $\mathrm{S}$ in coals and chars will be investigated.

As a complement to the XAFS analysis mentioned above, a unique protocol developed by USGS will be used in Task 4 to analyze selected raw coal, and size and density segregated coal, samples for trace element forms of occurrence. This protocol combines low temperature $\left(<200^{\circ} \mathrm{C}\right)$ ashing, chemical analysis, x-ray diffraction, coal segregation via flotation, ammonium acetate and selected acid leaching, electron microbeam measurements, and low and moderate temperature heating tests to determine the forms of elements in coal. Because of the unique combination of existing testing and analytical facilities available at USGS, the work will be conducted at USGS laboratories. 


\section{Combustion Zone Transformations}

The effect of coal type and combustion conditions on the emission of the toxic trace elements will be investigated using the UU laminar-flow drop tube reactor (Task 5.1). The fundamental mechanisms of toxic species formation and partitioning will be determined from careful examination of the ash formed under a variety of combustion conditions. Measurements will be made of the partitioning of the trace elements in the three coals as a function of temperature and equivalence ratio. These measurements will provide the baseline data on the fraction vaporized. Individual size-segregated ash samples (collected with a cascade impactor) will then be analyzed by NAA for total composition and other analyses as needed, for example, Auger and STEM for surface composition, TEM and SEM for particle morphology, and possibly water washing and/or chemical leaching to determine the solubility of selected trace elements in the ash samples. Samples will also be submitted to UK for chemical species analysis by XAFS and other techniques.

\section{Post-Combustion Transformations}

The goal of this task is an increased understanding of the transformations of selected metals as the flue gases cool following the high temperature combustion zone. Bench scale experimentation will be carried out by several organizations as well as large scale combustion measurements. Advanced analytical methods will be used extensively to understand speciation of trace elements in the post-combustion flue gas.

At the UC (Task 10) experiments will focus on determination of trace vapor-ash particle reactions rates in post-combustion gases, including

- Identification of the rate controlling phenomena in the oxidation of arsenic under combustion conditions

- $\quad$ Relative rates of gas-phase reaction of elemental mercury with $\mathrm{HCl}$ and $\mathrm{Cl}_{2}$ under combustion conditions

- Measurement of rates of heterogeneous conversion of $\mathrm{HCl}$ to $\mathrm{Cl}_{2}$ in the presence of coal combustion products such as iron oxide, iron sulfate, and fly ash samples.

Interactions of mercury with ash and ash components at lower temperatures will be the focus of the effort at EERC in Task 11. A bench-scale sorbent evaluation system will be used to increase our understanding of the interactions between gas-phase mercury and coal ash. Experiments will explore the effects of temperature and the interactions between elemental mercury or mercuric chloride and fly ash samples generated under oxidizing conditions, the effect of mercury concentration on the interactions between elemental mercury and fly ash, and the effect of coal combustion conditions on the ash and ultimately on the interaction between mercury and ash. 
On a larger scale in Task 6, UA will determine how both coal composition, detailed mineralogy and combustion conditions (including low $\mathrm{NO}_{\mathrm{x}}$ conditions) govern the fate of toxic metals under practical time/temperature, self sustained, yet still aerodynamically well defined, pulverized coal combustion conditions. Program coals will be burned in the UA self-sustained combustor under premixed conditions. The baseline tests will employ the naturally occurring temperature profile for each coal at a stoichiometric ratio of 1.2. Samples will be withdrawn at several ports, representing a range of temperatures and residence times. Complete impactor samples will be collected and analyzed for each toxic metal (11 as listed in the CAAA plus U and Th) plus major elements. This will yield the particle size segregated toxic metal composition, which can be compared to data obtained from other tasks of this program. These data will then be examined to determine particle size dependence in order to infer possible mechanisms governing the fate of each metal.

\section{Model Validation}

UC will conduct a more in-depth review of the relevant field data on inorganic emissions (Task 9.2). In Phase II we will emphasize use the field data to validate the models we will develop. The Phase II effort focuses on data from the following sources:
- $\quad$ EPRI PISCES
- DOE Program
- $\quad$ VTT (Finland)
- $\quad$ KEMA (Netherlands).

Important issues to be addressed when reviewing these data include mass balance closure, methods of analysis and sample collection, effect of APCD, effect of bulk coal ash chemistry, particle size distribution, and speciation of $\mathrm{Hg}$.

\section{Model Development}

In Task 9.1, data obtained from subcontractor and PSI tasks will be combined to create a comprehensive model of the transformations of important inorganic species during combustion. This model, denoted the ToPEM, will be based on an existing model (the PSI Engineering Model for Ash Formation which predicts ash particle size and composition distributions - EMAF). Because the development of this model is strongly dependent on the mechanistic, equilibrium, and kinetic information being developed under the experimental tasks, ToPEM will incorporate information on the mechanisms controlling species behavior, equilibrium modeling where appropriate and kinetic modeling to mimic kinetic constraints on species behavior. During the later stages of the Phase II work, sufficient detailed information will be available to support specific modifications to EMAF in order to describe the combustion transformations of important inorganic trace elements. Based on the experimental studies, equilibrium modeling, and kinetic modeling, it will be clear which modifications are required. Once complete, the model will be validated using a combination of laboratory and field data. As part of the validation effort, coal and size fractionated ash samples collected from operating utility boilers will be provided by Dr. Esko Kauppinen of VTT, Finland. Once validated, the ToPEM will be used to simulate the 
behavior of these and other coals under utility boiler conditions. The results from these simulations will then be compared to field data from PISCES obtained through EPRI participation in this program, DOE field sampling campaigns, and other relevant data in the literature. This validation procedure will ensure that the model developed as the result of the proposed research efforts accurately predicts the behavior of toxic metals species from a wide range of coals during the combustion process in any combustion system. 


\section{SECTION 3}

RESULTS AND DISCUSSION

$3-1 / 3-2$ 


\section{RESULTS AND DISCUSSION}

\subsection{Program Management (PSI)}

On December 17, PSI was visited by Professor Hiroshi Moritomi of Gifu University and Mr. Naoki Fujiwara of Idemitsu Kosan, Coal Research Laboratory. They came to PSI to learn about our work in the area of toxic elements in coal combustion systems. They also visited Prof. Wendt at the University of Arizona and Dr. Bill Linak at EPA RTP in this trip. Prof. Moritomi is working on a nationally-funded program (CREST) now and anticipates additional funding next year from Idemitsu Kosan for the project on trace metals. Mr. Fujuwara described the "Environmentally Friendly Coal Combustion" project, part of MITI's next-generation coal utilization technology development (NEDO) program. Next year, a separate project under NEDO will be established for trace elements in pulverized-coal (pc) combustion. The project was proposed to be 3 years and 270 million yen. (This is similar in size to this DOE-sponsored toxics program.) There are three tasks in this program: 1) Review of current work (mechanisms, measurement methods, removal methods); 2) Development of analysis systems for toxic metals, including CEMs; and 3) Development of removal techniques for toxic elements, primarily mercury.

\subsection{Coal Characterization (UK, USGS, MIT)}

\subsubsection{Coal Properties}

Basic coal testing at USGS is now complete and these results are summarized in Table 3-1. The results show moisture contents ranging from $2.33 \mathrm{wt} \cdot \%$ for the Ohio coal to $35.88 \mathrm{wt} . \%$ for the North Dakota Falkirk lignite sample. The Wyodak and North Dakota samples will require that geochemical results for these samples be corrected to account for their high moisture contents.

Table 3-1. Summary of Coal Characteristics for Phase II Coals (in weight percent, dry basis)

\begin{tabular}{|l|c|c|c|}
\hline & Ohio 5/6/7 & North Dakota & Wyodak \\
\hline \hline Ash & 9.93 & 14.64 & 8.13 \\
\hline Pyritic Sulfur & 1.42 & 0.28 & 0.05 \\
\hline Organic Sulfur & 1.24 & 0.56 & 0.37 \\
\hline Sulfate Sulfur & 0.02 & 0.14 & 0.01 \\
\hline Moisture & 2.33 & 35.88 & 25.81 \\
\hline Rank & Bituminous & Lignite & Subbituminous \\
\hline
\end{tabular}


Ash contents for the three Phase II coals range from $8.1 \%$ in the Wyodak to $14.6 \%$ in the North Dakota sample, reported on a dry basis. Total sulfur contents range from $0.43 \mathrm{wt} . \%$ in the Wyodak to $2.68 \mathrm{wt} \cdot \%$ in the Ohio sample. In the Ohio sample, about half of the total sulfur is pyritic and half is organic. In the North Dakota sample (total sulfur $0.98 \mathrm{wt} \cdot \%$ ), the organic sulfur content is $0.56 \mathrm{wt} \cdot \%$, and the pyritic sulfur fraction is exactly half that of the organic sulfur. The remainder of the sulfur in the North Dakota sample $(0.14 \%)$ is present as sulfate, consistent with the presence of barite in this sample. In the Wyodak sample, the majority of the sulfur is organic.

\subsubsection{Coal Mineralogy}

Mineralogy of the three Phase II coals was determined by SEM/EDX and is summarized in Table 3-2. The Ohio coal contains all of the five most common major phases: quartz, illitic clay, kaolinitic clay, pyrite and calcite. The illite grains in this sample are large (some larger than $50 \mu \mathrm{m}$ ) and well formed, and may be appropriate for follow-up studies on $\mathrm{Cr}$ distribution using the ion probe. Based on this preliminary work, the North Dakota sample appears to lack both kaolinite and calcite, and the Wyodak sample appears to lack calcite.

The minor or trace phases found and their compositions are shown in the lower part of Table 3-2. Each of the three samples contains a $\mathrm{TiO}_{2}$ phase (probably rutile), monazite (REE phosphate) and sphalerite $(\mathrm{ZnS})$. Barite $\left(\mathrm{BaSO}_{4}\right)$ and an iron-oxide or hydroxide phase are common in both the North Dakota and Wyodak samples. An interesting suite of accessory silicates is present in the North Dakota sample, including epidote, chlorite, and probable, alkalifeldspar. The presence of these phases is suggestive of a metamorphic contribution to the coal basin. Subsequent SEM work will attempt to reconfirm the basic findings presented here, and identify additional trace phases that could host the elements of interest in this study.

\subsubsection{Forms of Occurrence of Trace Elements by Microprobe and Leaching Analyses}

At the present time, selective leaching procedures for the Ohio and North Dakota samples have been completed, and a portion (INAA and ICP-AES acid digest) of the analytical results have been returned. The Wyodak sample was received after these two samples, and is currently in the final stage of the leaching procedure. Preliminary leaching results for the Ohio and North Dakota samples are presented in Table 3-3, based only on INAA and CVAA (Hg) results on the bulk starting material and the solid residues after each leaching step. Final values for percentages leached and the trace-element composition of the starting coals will be reported when all of the analyses are available. Because the analytical results are incomplete, we have chosen to limit the discussion to INAA leaching results for five elements of interest: $\mathrm{As}, \mathrm{Fe}, \mathrm{Cr}, \mathrm{Se}$, and $\mathrm{Hg}$ (Table 3-3). Also included in Table 3-3 are whole-coal INAA values for these elements.

Preliminary leaching results for arsenic and iron show considerable parallels and results for these elements should be considered together. In the North Dakota sample, the largest portions of each element are removed by ammonium acetate and $\mathrm{HCl}$, and leaching totals are in the 70 to $80 \%$ range. In the Ohio sample, small amounts of $\mathrm{As}$ and $\mathrm{Fe}$ are leached by $\mathrm{HCl}, \mathrm{HF}$, and $\mathrm{HNO}_{3}$, with large (65 to 70\%) fractions unleached. Given the amount of pyrite in this sample 
Table 3-2. Preliminary Mineralogy- Phase II Coals (SEM Only)

\begin{tabular}{|c|c|c|c|c|}
\hline \multicolumn{2}{|c|}{ Major Phases } & Ohio & North Dakota & Wyodak \\
\hline \multicolumn{2}{|l|}{ Quartz } & $\mathrm{X}$ & $\mathrm{X}$ & $\mathrm{X}$ \\
\hline \multicolumn{2}{|l|}{ Illite } & $\mathrm{X}$ & $\mathrm{X}$ & $\mathrm{X}$ \\
\hline \multicolumn{2}{|l|}{ Kaolinite } & $X$ & & $\mathrm{X}$ \\
\hline \multicolumn{2}{|l|}{ Pyrite } & $\mathrm{X}$ & $\mathrm{X}$ & $\mathrm{X}$ \\
\hline \multicolumn{2}{|l|}{ Calcite } & $X$ & & \\
\hline \multicolumn{5}{|c|}{ Minor or Trace Phases } \\
\hline Epidote & Fe-Mg-Ca-Al silicate & & $\mathrm{X}$ & \\
\hline Chlorite & Fe-Mg-Al silicate & & $\mathrm{X}$ & \\
\hline Alkali-feldspar & K-Al-silicate & & $\mathrm{X}$ & \\
\hline Zircon & $\mathrm{ZrSiO}_{4}$ & & & $\mathrm{X}$ \\
\hline Barite & $\mathrm{BaSO}_{4}$ & & $\mathrm{X}$ & $\mathrm{X}$ \\
\hline $\mathrm{Fe}-0(\mathrm{OH})$ phase & & & $\mathrm{X}$ & $\mathrm{X}$ \\
\hline $\mathrm{TiO}_{2}$ phase & & $X$ & $\mathrm{X}$ & $\mathrm{X}$ \\
\hline Apatite & Ca-phosphate & $\mathrm{X}$ & $\mathrm{X}$ & \\
\hline Crandellite & Ca-Al phosphate & & & $\mathrm{X}$ \\
\hline Goyazite & Sr-Al-REE phosphate & & $X$ & \\
\hline Monazite & REE phosphate & $\mathrm{X}$ & $\mathrm{X}$ & $\mathrm{X}$ \\
\hline Sphalerite & $\mathrm{ZnS}$ & $X$ & $\mathrm{X}$ & $\mathrm{X}$ \\
\hline Chalcopyrite & $\mathrm{CuFeS}_{2}$ & & & $\mathrm{X}$ \\
\hline
\end{tabular}

(2.7 wt.\%, calculated from the pyritic sulfur value), and our experience with other bituminous coals in the Northern Appalachian region, we consider the $\mathrm{HNO}_{3}$ leaching data to be in error, probably due to a problem with the normality of the acid. If this is the case, each of the $\mathrm{HNO}_{3}$ leaching values reported in Table 3-3 is in error to a varying degree, and consequently, these are shown with italics and are underlined. The likely presence of unleached pyrite in the Ohio solid residue will be confirmed by SEM, and this will be followed by a repeat of the leaching procedure for the Ohio and North Dakota samples. This problem should not affect the preliminary leaching results for ammonium acetate, $\mathrm{HCl}$ and $\mathrm{HF}$ reported in Table 3-3, or any of the leaching results for the Wyodak sample done subsequently. 
Table 3-3. Preliminary Leaching Data, INAA Only (Hg by CVAA)

\begin{tabular}{|c|c|c|c|c|c|}
\hline Element/Coal & $\mathrm{CH}_{3} \mathrm{COONH}_{4}$ & $\mathrm{HCl}$ & $\mathrm{HF}$ & $\mathrm{HNO}_{3}$ & Unleached \\
\hline $\begin{array}{l}\text { As (ppm) } \\
\text { Ohio } 16.5 \\
\text { N. Dakota } 9.9\end{array}$ & $\begin{array}{r}0 \\
35\end{array}$ & $\begin{array}{l}20 \\
25\end{array}$ & $\begin{array}{r}5 \\
10\end{array}$ & $\frac{10}{\underline{0}}$ & $\begin{array}{c}65 \\
30\end{array}$ \\
\hline $\begin{array}{ll}\mathrm{Fe}(\mathrm{wt} \cdot \%) & \\
\text { Ohio } & 1.43 \\
\text { N. Dakota } & 0.79\end{array}$ & $\begin{array}{r}0 \\
35\end{array}$ & $\begin{array}{l}15 \\
35\end{array}$ & $\begin{array}{r}5 \\
10\end{array}$ & $\frac{10}{\underline{0}}$ & $\begin{array}{l}70 \\
20\end{array}$ \\
\hline $\begin{array}{ll}\mathrm{Cr}(\mathrm{ppm}) & \\
\text { Ohio } & 15.0 \\
\text { N. Dakota } & 11.8\end{array}$ & $\begin{array}{r}0 \\
35\end{array}$ & $\begin{array}{r}0 \\
10\end{array}$ & $\begin{array}{l}25 \\
30\end{array}$ & $\underline{\underline{5}}$ & $\begin{array}{l}70 \\
25\end{array}$ \\
\hline $\begin{array}{ll}\underline{\mathrm{Se}(\mathrm{ppm})} & \\
\text { Ohio } & 1.8 \\
\text { N. Dakota } & 0.94\end{array}$ & $\begin{array}{l}10 \\
20\end{array}$ & $\begin{array}{r}0 \\
15\end{array}$ & $\begin{array}{r}0 \\
15\end{array}$ & $\underline{\underline{0}}$ & $\begin{array}{l}90 \\
50\end{array}$ \\
\hline $\begin{array}{ll}\mathrm{Hg}(\mathrm{ppm}) & \\
\text { Ohio } & 0.18 \\
\text { N. Dakota } & 0.05\end{array}$ & $\begin{array}{l}5 \\
0\end{array}$ & $\begin{array}{r}0 \\
20\end{array}$ & $\begin{array}{r}15 \\
0\end{array}$ & $\underline{\underline{0}}$ & $\begin{array}{l}80 \\
80\end{array}$ \\
\hline
\end{tabular}

Preliminary leaching results for chromium indicate a significant aluminosilicate-hosted fraction (25 to 30\% HF leachable) in each of the two coals determined. Preliminary results for Se and $\mathrm{Hg}$ show large unleached fractions (50 to 90\%) suggestive of incomplete pyrite digestion, as indicated above.

Electron microprobe analyses were obtained for a number of pyrite grains in each of the three Phase II coals (Figures 3-1 through 3-3; Appendix A). Elements determined include $\mathrm{Pb}, \mathrm{Se}$, $\mathrm{Cu}, \mathrm{Cd}, \mathrm{As}, \mathrm{Ni}, \mathrm{Zn}, \mathrm{Co}, \mathrm{Fe}$, and $\mathrm{S}$. Analytical methods are similar to those used in Phase I, except that $\mathrm{Pb}$ has been added to the procedure. Each of the analyses plotted and listed represents a $\sim 3 \mu \mathrm{m}$ spot, and individual pyrite grains are represented by one to six spot analyses (Appendix A). The most commonly encountered pyrite forms include subhedral, irregular, and framboidal. The data are not sufficient to make generalizations about trace-element differences among the various forms, or to approximate average concentrations of these elements in pyrite for each sample.

The largest pyrite grains, up to nearly $200 \mu \mathrm{m}$ in maximum dimension, occur in the Ohio sample, but as shown by Figure 3-1, these grains appear to be among the lowest in As. Some of the smaller pyrite grains in this sample have higher As contents, but in no case does this exceed about $0.35 \mathrm{wt} \%$. Pyrite grains in the North Dakota and Wyodak coals are generally small $(<5$ to about $75 \mu \mathrm{m}$ ) and show a range of As contents below about $0.25 \mathrm{wt} . \%$ (note: grain sizes represent grains chosen for microprobe analysis and are not the result of a systematic grain-size analysis). 


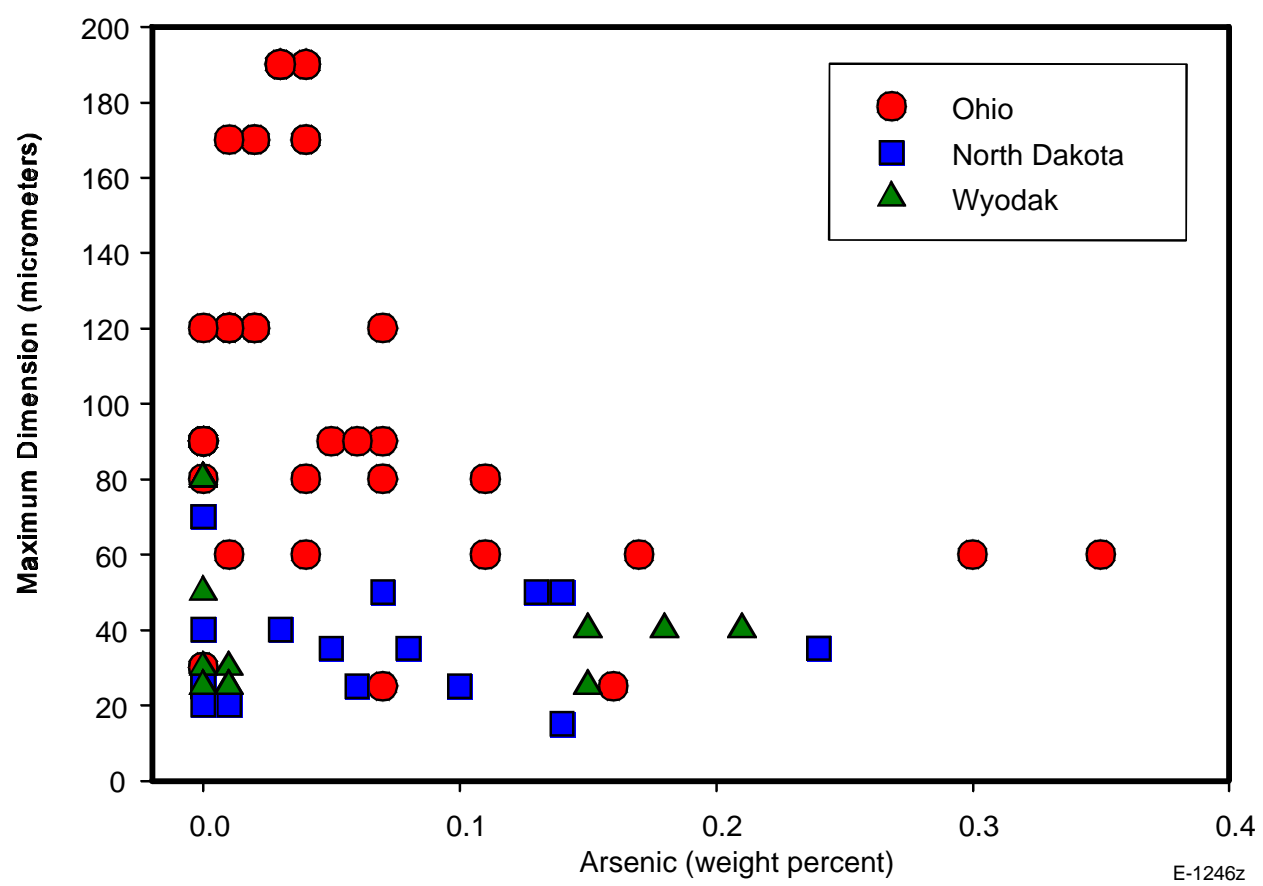

Figure 3-1. Plot of arsenic weight percent versus maximum dimension of analyzed pyrite grains in the three Phase II coals. Diagram shows large size and compositional range for Ohio 5/6/7 pyrite grains, and similar compositional range but more limited size range for North Dakota and Wyodak samples.

Microprobe data for $\mathrm{Ni}$, and $\mathrm{Pb}$ in pyrite are plotted versus As in Figures 3-2 and 3-3, respectively. Neither element shows a particularly good correlation with arsenic enrichment in pyrite.

Cold vapor atomic fluorescence (CVAF) development work for $\mathrm{Hg}$ analyses is ongoing in Denver. Trials indicate that the minimum detection limit by this method is limited by a total analytical blank level in the 0.01 to $0.02 \mathrm{ppm}$ (10 to $20 \mathrm{ppb}$ ) range, similar to the detection limit for the previous (CVAA) method. Reagents used in this procedure include nitric acid, sulfuric acid, and vanadium pentoxide. It appears that the blank is controlled by $\mathrm{V}_{2} \mathrm{O}_{5}$ (30 to 40 parts per trillion (ppt)) versus <2 ppt for each of the acids. As an interim step, $\mathrm{Hg}$ analyses will be done by CVAA, in parallel with CVAF development. Once an acceptable CVAF blank level is attained, the analyses will be repeated as necessary.

At the time of this report, both USGS-University of Kentucky Phase I manuscripts for Fuel Processing Technology have been reviewed. The Cr manuscript ${ }^{1}$ has cleared the internal USGS review process and favorable external reviews have been returned. The As manuscript ${ }^{2}$ has also cleared USGS internal review and we are awaiting return of the external reviews. 


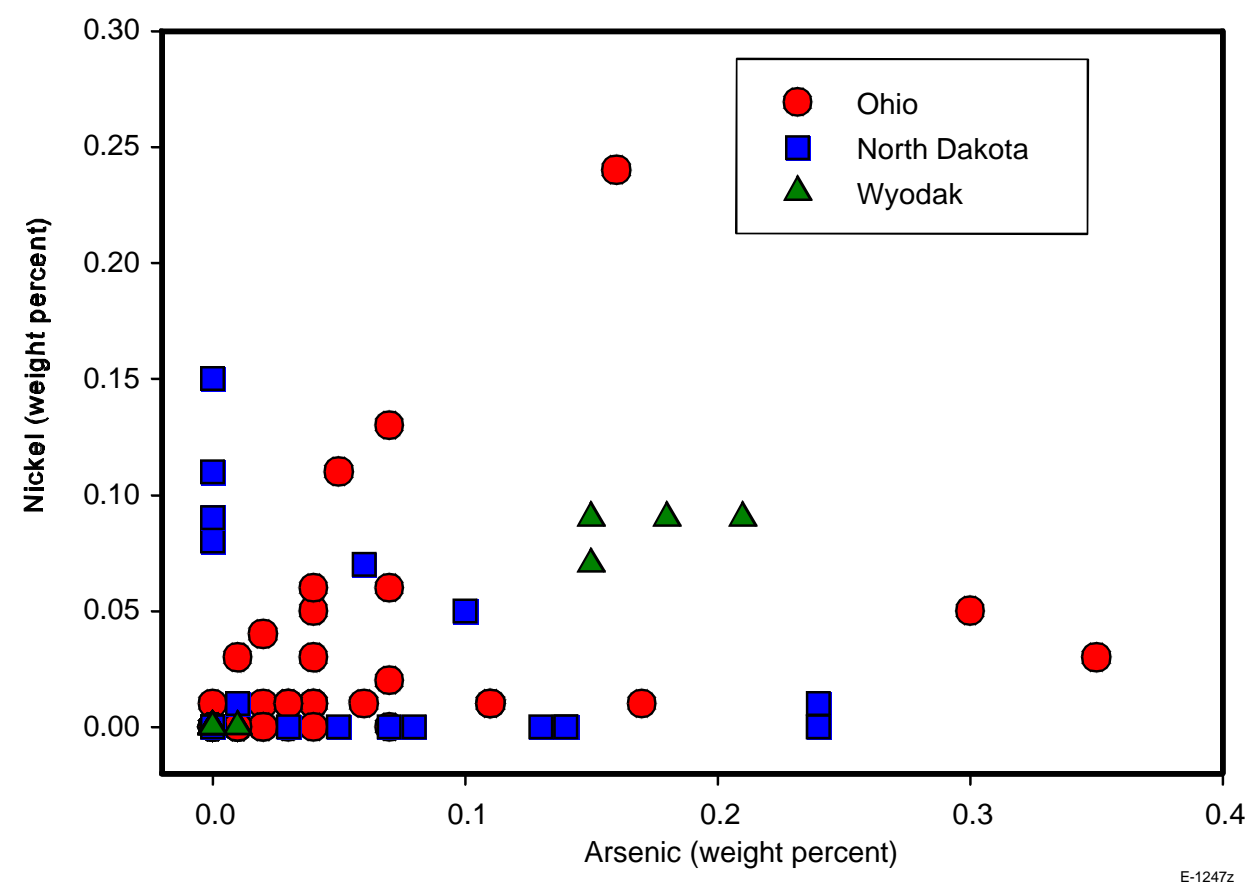

Figure 3-2. Plot of arsenic versus nickel in Phase II pyrites. Diagram shows a general lack of correlation in the enrichment of these elements, but exceptions are evident in each of the three pyrite populations.

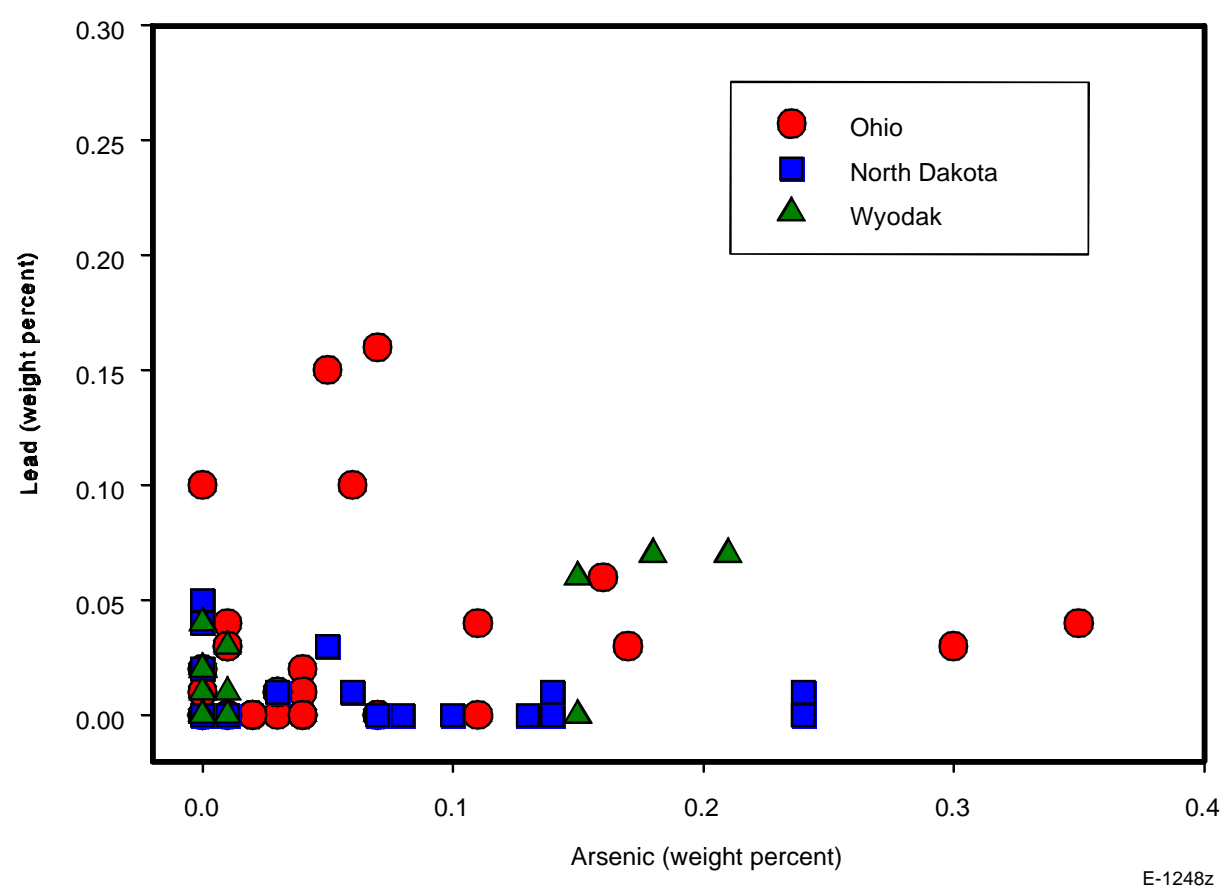

Figure 3-3. Plot of arsenic versus lead in Phase II pyrite grains. Diagram shows that measurable (above detection limit) $\mathrm{Pb}$ values were obtained for pyrite in each of the three coals. 


\subsubsection{Forms of Occurrence of Trace Elements by XAFS}

Analysis of Se XAFS data obtained at NSLS in July, 1998, for the Ohio and North Dakota coals was attempted during the quarter. But the data were poor with relatively high noise (Figure 3-4), reflecting the fact that both coals contain only about $1.5 \mathrm{ppm}$ Se and the data collection was not long enough, especially for the North Dakota Falkirk lignite. New Se XAFS data will be collected for all project coals during our next synchrotron session at SSRL in February, 1999. However, despite the relatively poor quality of the data, the Se XANES spectra for the Ohio coal do appear to indicate a significant $\mathrm{Se} /$ pyrite association.

Data were also obtained for chromium in some of the project coals and fractions during a synchrotron session at NSLS in November 1998. The data collection for chromium in the project coals will be completed in February 1999, during our next experimental session at SSRL and discussion of the results will be deferred until after all the data are collected.

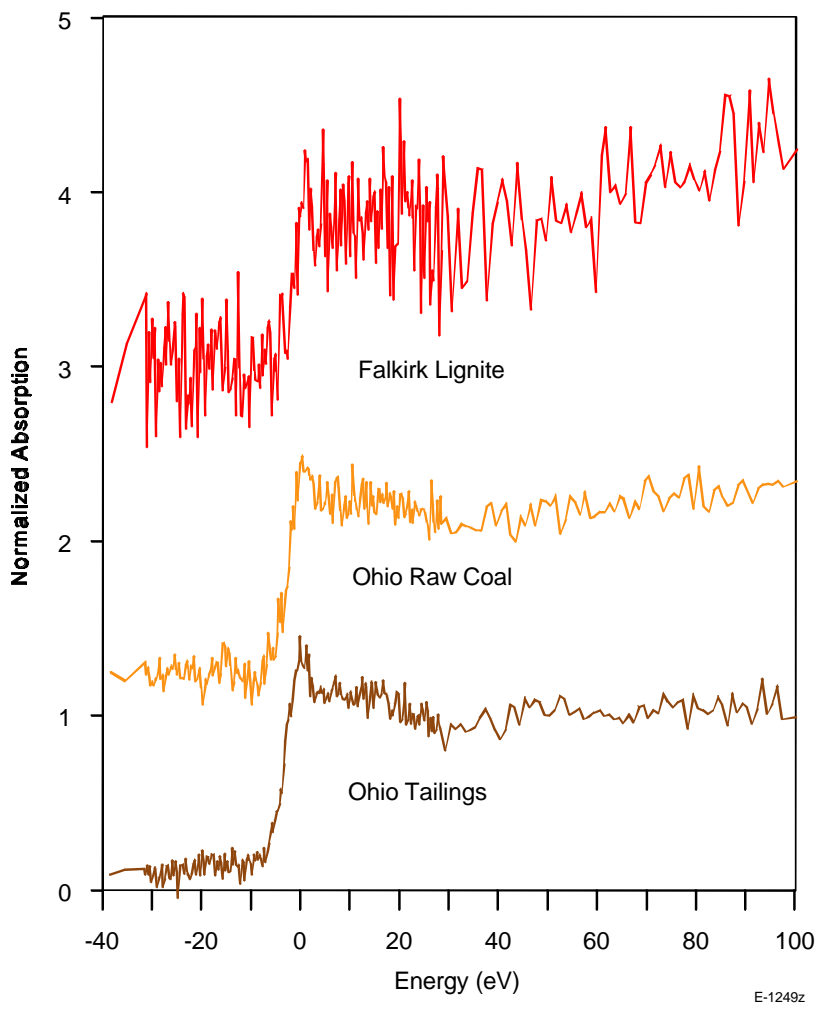

Figure 3-4. Selenium XANES spectrum of Ohio bituminous coal and tailings fraction and of the North Dakota lignite

A new fraction of the Ohio coal, a 2.88 sink fraction, was prepared during the quarter. This sample completes the fractionation of the Ohio project coal for XAFS speciation investigations. As described below, instead of performing float/sink fractionation on the two lowrank coals, we will examine fractions of the leached residues prepared in the USGS leaching protocol. Examination of these fractions will be advantageous to both the XAFS and leaching speciation studies.

Reviews have been received for the chromium speciation paper submitted to the AirToxics Special Issue of Fuel Processing Technology ${ }^{1}$ and a revised version of the paper is currently being prepared. A paper on Hg XANES systematics of carbon-based sorbents has been accepted for publication in the Japanese Journal of Applied Physics. ${ }^{3}$ An earlier paper on mercury sorption, based on work carried out in Phase I of the study, will appear in the January/February issue of Energy \& Fuels. ${ }^{4}$ 


\subsection{Combustion Zone Transformations (UU, MIT)}

\subsubsection{Metal Vaporization at Devolatilization Temperature}

The goal of this experimental series is to determine whether metals are vaporized at the low temperatures typical of the devolatization stage of pulverized coal combustion. The heating conditions selected were those used for an ASTM volatiles determination. Duplicate samples of both the parent coal and the fixed carbon were prepared for seven coals. The fixed carbon was produced by heating a $1 \mathrm{~g}$ sample in a covered quartz crucible for $7 \mathrm{~min}$ at $950^{\circ} \mathrm{C}$. These samples have been sent to Michael Ames at MIT for elemental analysis by neutron activation.

Several techniques were used to insure data quality. Samples of standard reference material NIST 1633b Constituent Elements in Coal Fly Ash were used as a control to detect contamination during the handling procedures. The weight loss during the sample heating was within the range of literature values or prior analysis for the parent coal indicating that the procedures used to generate the samples were reproducible and were consistent with ASTM volatiles tests run at other sites. Calculations indicate that the actual volume of gas produced during devolatization is at least 10 to 20 times the head space in the covered crucible, depending on the assumed molecular weight of the organic gas mixture. This indicates that metals vaporized are vented from the crucible, and that recondensation of vaporized metals during sample cooldown is not a serious problem.

\subsubsection{Transfer of the MIT Oxidation Drop Tube Furnace at the University of Utah}

The Oxidation Drop Tube is a Laminar, Entrained Flow Reactor which allows one to conduct tests at high temperature (up to $1750 \mathrm{~K}$ ) under a wide range of atmospheres, ranging from inert to pure oxygen. The energy is provided by an Astro model 1000A-3560 graphite element furnace. Its design is optimum for the study of reaction kinetics at times up to a second, but can also be used for longer times by placing particles in the heated zone in a crucible.

The furnace has been used for studying a range of problems including ultra-fine particle formation, ash transformations, coal devolatilization, char oxidation, flash smelting, NO char reactions, $\mathrm{SO}_{3}$ formation, $\mathrm{SO}_{2}$ capture. Some of these studies led to the following publications,

- $\quad$ Pohl, J., and Sarofim, A. "Devolatilization and Oxidation of Coal Nitrogen." Sixteenth Symposium (International) on Combustion/The Combustion Institute 1976, 491.

- $\quad$ Neville, M., Quann, R. J., Haynes, B. S., and Sarofim, A. F. "Vaporization and condensation of Mineral Matter During Pulverized Coal Combustion." Eighteenth Symposium (International) on Combustion/The Combustion Institute 1980, 1267.

- $\quad$ Levy, J., Chan, A., Sarofim, A., and Beér, J. "NO/Char Reactions at Pulverized Coal Flame Conditions." Eighteenth Symposium (International) on Combustion/The Combustion Institute 1981, 111.

- $\quad$ Song, Y., Pohl, J., Beér, J., and Sarofim, A. Nitric Oxide Formation During Pulverized Coal Combustion." Combust. Sci. and Tech. 1982, 28, 31. 
- $\quad$ Song, Y., Beér, J., and Sarofim, A. "Oxidation and Devolatilization of Nitrogen in Coal Char." Combust. Sci. and Tech. 1982, 28, 177.

- $\quad$ Chan, L., Sarofim, A., and Beér, J. "Kinetics of the NO-Carbon Reaction at Fluidized Bed Combustion." Combustion and Flame 1983, 52, 37.

- $\quad$ Torres-Ordonez, R. J., Longwell, J. P., and Sarofim, A. F. "Intrinsic Kinetics of CaS(s) Oxidation." Energy Fuels 1989, 506.

- Torres-Ordonez, R. J., Longwell, J. P., and Sarofim, A. F. "Physical Transformations During CaS(s) Oxidation." Energy Fuels 1989, 595.

- Helbe, J. J., and Sarofim, A. F. "Influence of Char Fragmentation on Ash Particle Size Distribution." Combustion and Flame 1989, 183.

- Wornat, M. J., and Sarofim, A. F. "Char- and Aerosol-Associated Polycyclic Aromatic Compounds from Coal Pyrolysis. Relationship Between Particle Size and Surface Composition." Aerosol Science and Technology 1990, 832.

- Graham, K., and Sarofim, A. F. "Inorganic Aerosol and their Role in Catalyzing Sulfuric Acid Production in Furnaces." Journal of the Air \& Waste Management Association 1997, 48, 106.

Considering the importance of the drop tube furnace as an effective research tool for studying reactions at high temperature, one of these units that was previously at MIT was transferred to the Combustion Research Laboratory of the University of Utah. Figure 3-5 presents a photograph of the final setup of this unit at the Combustion Laboratory, University of Utah.

The transfer process involved the design of a semi-closed cooling system as well as the reconstruction of the gas and particle feeding units and of the particles and gas collecting facilities. Figure 3-6 presents a schematic layout of the Drop Tube Unit including particle injection and collecting systems.

\subsubsection{Measurement of Gas-Phase Mercury and Other Trace Metals}

The Massachusetts Institute of Technology has re-tested its iodated charcoal sorbent traps for the collection of $\mathrm{Hg}^{0}$ and $\mathrm{HgCl}_{2}$. The $100 \mathrm{mg}$ traps were verified to be $100 \%$ efficient for total $\mathrm{Hg}$ collection at a gas flow rate of 1 liter per minute. The $\mathrm{Hg}$ blank level in these traps is $1 \mathrm{ng}$. Therefore a reliable analysis of sampled $\mathrm{Hg}$ requires that at least a few nanograms of $\mathrm{Hg}$ be collected. Considering that the $\mathrm{Hg}$ concentrations in the Phase II coals is 130 to $150 \mathrm{ng} / \mathrm{g}$, this requirement for a few nanograms of collected $\mathrm{Hg}$ should be readily attainable in even the very small combustors/reactors. Progress has been made in the development of a dry system for the separate collection of $\mathrm{HgCl}_{2}$ and $\mathrm{Hg}^{0}$ which should be simpler to use than the Ontario Hydro impinger method and which will use a collection medium for $\mathrm{HgCl}_{2}$ suitable for analysis by neutron activation. 


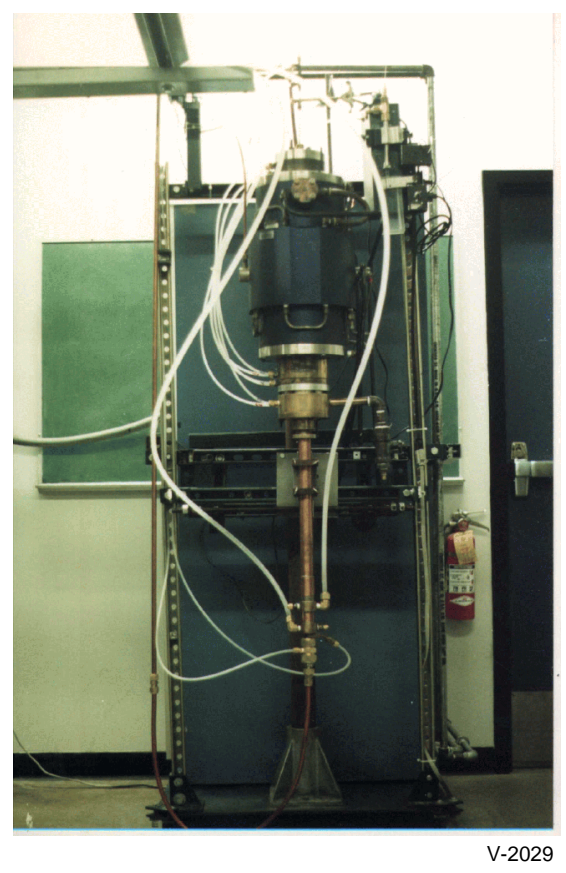

Figure 3-5. Oxidation Drop Tube Furnace at the University of Utah.

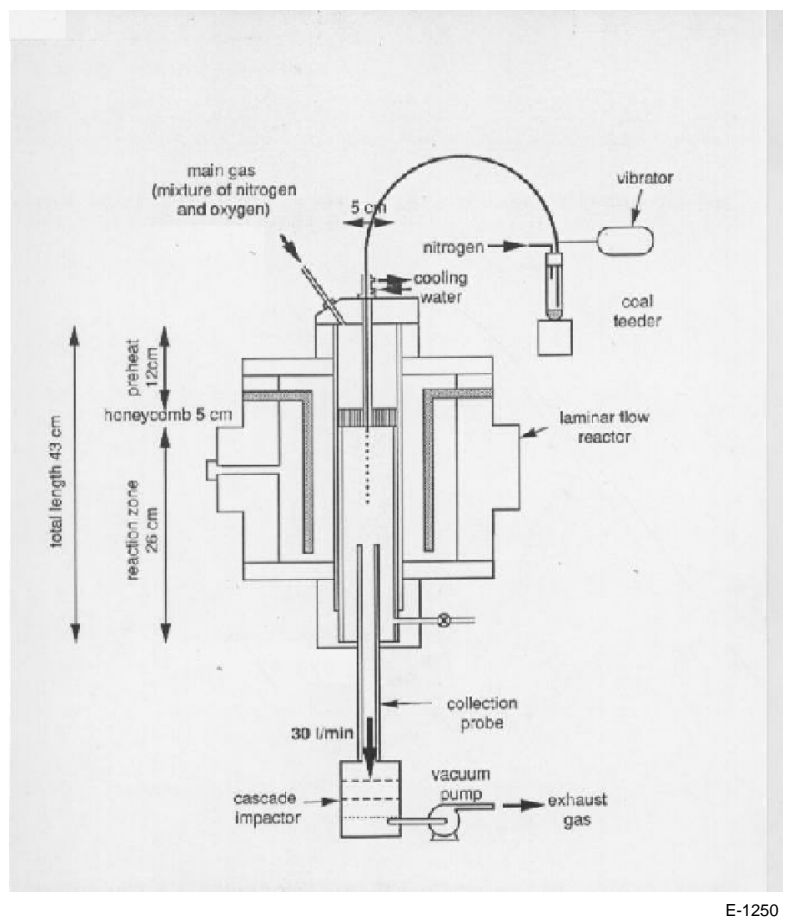

Figure 3-6. Schematic of the Oxidation Drop Tube Furnace. 


\section{$3.4 \quad$ Post-Combustion Transformations (UA, UC, UU)}

\subsubsection{Large Scale Integrated Combustion Studies}

The University of Arizona's pilot-scale downflow laboratory combustion furnace was used to test the partitioning of toxic metals in the Phase II baseline experiments for the Ohio 5/6/7 blend coal. The objectives of these experiments were:

- To obtain toxic metal partitioning data under test conditions which simulate the time/ temperature combustion and post-combustion conditions of commercial scale utility boilers at $20 \%$ excess oxygen.

- $\quad$ To investigate the differences in toxic metal partitioning from samples collected immediately after char burnout compared to samples collected near the furnace exit and to samples collected at the entrance to the baghouse.

A detailed description of the furnace and sampling systems is given in the Phase I Final Report. As described in the previous quarterly report, covering July through September 1998, the furnace was completely rebuilt. The locations of particulate sample parts were appoximately the same as before. A Berner low pressure impactor (BLPI) was used for particulate sample collection for all of the experiments performed.

Sample collection media for the BLPI consisted of polycarbonate membranes sprayed with a high purity grease. The membranes were dried in a vacuum dessicator for a minimum of 3 hours. One-and-one-half-milliliter PVC sample vials were used to contain the particulate-laden membranes. The vials were weighed with and without the particulate-laden membranes on a microbalance and stored in zip-loc sealed polyethylene bags. The dried sample media were also weighed on the microbalance just prior to loading into the BLPI. All microbalance weights were repeated. Two readings with a deviation of less than $0.00003 \mathrm{~g}$ were required before the weight data were accepted as accurate.

A total of 16 sets of particulate samples were collected during nine test runs. [Note that a sample set consists of six membranes from a first collection test for particulate on atmospheric plates of the BLPI without the cyclone on the BLPI inlet and six membranes from a second collection test performed immediately before or after the first test collecting particulate on the sub-atmospheric plates of the BLPI with a cyclone.] Seven sets of particulate samples were collected from Port 4 of the furnace, which is located immediately after the end of the combustion zone (around 0.5 residence seconds from the burner). This port is at approximately the same location as Port 4B, used in the Phase I experiments.

Five sets of particulate samples were collected from Port 14, which is located near the bottom of the furnace (around 2.2 residence seconds from the burner) and represents a snapshot of the flue gas in the post-combustion zone. This port is at approximately the same location as Port 12, used in the Phase I experiments. These five samples sets were taken immediately after one of the sample sets from Port 4 so that matched sample sets could be selected for analysis. 
Table 3-4. Summary of the Phase II Ohio Baseline Test Runs

\begin{tabular}{|c|c|c|c|c|c|}
\hline Test Run \# & Date & Coal Feed Rate & Sample Set \# & Sampling Times & $\begin{array}{c}\text { Sample Port } \\
\text { Used } \\
\end{array}$ \\
\hline 980-1 & $11 / 19 / 98$ & $2.8 \mathrm{~kg} / \mathrm{hr}$ & none $^{\#}$ & & \\
\hline \multirow[t]{4}{*}{ 980-2 } & $11 / 21 / 98$ & $2.9 \mathrm{~kg} / \mathrm{hr}$ & $980-1 c^{*}$ & $2 \mathrm{hr}$ & 4 \\
\hline & & & $980-1^{*}$ & $4 \min$ & 4 \\
\hline & & & $980-2 c^{*}$ & $2 \mathrm{hr}$ & 14 \\
\hline & & & $980-2 *$ & $4 \min$ & 14 \\
\hline \multirow[t]{5}{*}{$980-3$} & $11 / 23 / 98$ & $2.6 \mathrm{~kg} / \mathrm{hr}$ & $980-3 c * *$ & $2 \mathrm{hr}$ & 4 \\
\hline & & & $980-3 * *$ & $4 \mathrm{~min}$ & 4 \\
\hline & & & $980-4 c$ & $30 \mathrm{~min}$ & 4 \\
\hline & & & $98 \mathrm{O}-5 \mathrm{c}$ & $30 \mathrm{~min}$ & 14 \\
\hline & & & $980-5$ & 45 seconds & 14 \\
\hline \multirow[t]{4}{*}{$980-4$} & 36122 & $2.6 \mathrm{~kg} / \mathrm{hr}$ & $980-6 c$ & $45 \mathrm{~min}$ & 4 \\
\hline & & & $980-6$ & 15 seconds & 4 \\
\hline & & & $980-7 c$ & $25 \mathrm{~min}$ & 14 \\
\hline & & & 980-7 & 10.2 seconds & 14 \\
\hline \multirow[t]{6}{*}{$980-5$} & 36126 & $2.6 \mathrm{~kg} / \mathrm{hr}$ & $980-8 c$ & $22 \min * *$ & 4 \\
\hline & & & $980-8$ & 10.3 seconds** & 4 \\
\hline & & & $980-9 c$ & $10 \mathrm{~min}$ & 4 \\
\hline & & & $980-9$ & 10.2 seconds & 4 \\
\hline & & & $980-10 c$ & $22 \mathrm{~min}$ & 14 \\
\hline & & & $980-10$ & 10.3 seconds & 14 \\
\hline \multirow[t]{4}{*}{ 980-6 } & 36128 & $2.8 \mathrm{~kg} / \mathrm{hr}$ & $980-11 c$ & $8 \mathrm{~min}$ & 4 \\
\hline & & & 980-11 & 40 seconds & 4 \\
\hline & & & $980-12 c$ & $1 \mathrm{hr}$ & 14 \\
\hline & & & $980-12$ & 45 seconds & 14 \\
\hline 980-7 & 36131 & $2.5 \mathrm{~kg} / \mathrm{hr}$ & none $^{\#}$ & & \\
\hline \multirow[t]{4}{*}{$980-8$} & 36149 & $2.4 \mathrm{~kg} / \mathrm{hr}$ & $980-13 c^{*}$ & $10 \mathrm{~min}$ & Baghouse \\
\hline & & & $980-13^{*}$ & $1 \mathrm{~min}$ & Baghouse \\
\hline & & & $980-14 c^{*}$ & $20 \mathrm{~min}$ & Baghouse \\
\hline & & & 980-14* & $6 \min$ & Baghouse \\
\hline \multirow[t]{3}{*}{$980-9$} & 36150 & $2.5 \mathrm{~kg} / \mathrm{hr}$ & $980-15 c$ & $25 \mathrm{~min}$ & Baghouse \\
\hline & & & $980-15$ & $6 \mathrm{~min}$ & Baghouse \\
\hline & & & $980-16$ & $30 \mathrm{~min}$ & Baghouse \\
\hline
\end{tabular}

\# Complete temperature and gas profiles were obtained using this run

*Sampling system problems encountered; results not valid

**Overloaded impactor; results not valid 
Four sample sets were taken from the inlet to the baghouse and represent hot-side ESP sampling conditions. The baghouse samples were taken after partial segregation of large particles in an ash trap and a small particle trap. Therefore, it was found that a single collection test, performed without the BLPI inlet cyclone, could be used to collect all 11 size-segregated samples from the BLPI. This was performed for sample set 16 only. The sample sets and test runs are summarized in Table 3-4. Table 3-5 shows the sampling conditions for the most important sample sets. Figure 3-7 shows the typical steady-state temperature profile from these tests.

Table 3-5. Summary of Experimental Sampling Conditions

\begin{tabular}{|c|c|c|c|c|c|c|c|}
\hline $\begin{array}{c}\text { Sample } \\
\text { Set \# } \\
\text { (Port } \\
\text { Sampled) }\end{array}$ & $\begin{array}{c}\text { Total } \\
\text { Combustion } \\
\text { Gas Rate } \\
\text { slpm) }\end{array}$ & $\begin{array}{c}\text { Sampling } \\
\text { Rate (slpm) }\end{array}$ & $\begin{array}{c}\text { Sampling } \\
\text { Temp. } \\
\left({ }^{\circ} \text { K at port }\right. \\
\text { where sample } \\
\text { was taken) }\end{array}$ & $\begin{array}{c}\text { Port 4 } \mathrm{O}_{2} \\
\text { Conc. } \\
(\%)\end{array}$ & $\begin{array}{c}\text { Port 4 } \mathrm{CO}_{2} \\
\text { Conc. } \\
(\%)\end{array}$ & $\begin{array}{c}\text { Port } 14 \mathrm{O}_{2} \\
\text { Conc. } \\
(\%)\end{array}$ & $\begin{array}{c}\text { Port } 14 \\
\mathrm{CO}_{2} \text { Conc. } \\
(\%)\end{array}$ \\
\hline $\begin{array}{c}98 \mathrm{O}-6 / 6 \mathrm{c} \\
(4)\end{array}$ & 425 & 1.62 & 1346 & 4.0 & 15.33 & & \\
\hline $\begin{array}{c}98 \mathrm{O}-7 / 7 \mathrm{c} \\
(12)\end{array}$ & 425 & 2.05 & 1060 & 3.9 & 15.4 & 6.3 & 13.7 \\
\hline $\begin{array}{c}98 \mathrm{O}-9 / 9 \mathrm{c} \\
(4 \mathrm{~b})\end{array}$ & 425 & 2.05 & $1308^{*}$ & $4.3^{*}$ & $14.6^{*}$ & & \\
\hline $\begin{array}{c}98 \mathrm{O}-10 / 10 \mathrm{c} \\
(12)\end{array}$ & 425 & 2.15 & 1032 & $4.3^{*}$ & $14.6^{*}$ & 8.5 & 11.1 \\
\hline $\begin{array}{c}98 \mathrm{O}-11 / 11 \mathrm{C} \\
(4 \mathrm{~b})\end{array}$ & 459 & 2.38 & 1331 & $3.5^{*}$ & $15.9^{*}$ & & \\
\hline $\begin{array}{c}98 \mathrm{O}-12 / 12 \mathrm{c} \\
(12)\end{array}$ & 459 & 2.55 & 1041 & $3.7^{*}$ & $15.6^{*}$ & 9.0 & 11.0 \\
\hline $\begin{array}{c}98 \mathrm{O}-16 \\
(4 \mathrm{~b})\end{array}$ & 401 & 1.20 & 612 & 4.3 & 15.2 & 6.4 & 13.5 \\
\hline
\end{tabular}

*Gas readings are from Port 3

Using the mass fractions from each test, an average mass loading can be calculated for each sampling location. The resulting particle size distributions are shown in Figures 3-8 and 3-9.

One representative sample set from Port 4, sample set number six, and the corresponding sample set from Port 14, sample set number 7, were selected for analysis of size-segregated particle metal content at MIT by NAA. Two representative samples sets from Port 4, sample sets nine and eleven, and the corresponding sample sets from Port 14, sample sets ten and twelve, plus one sample set from the baghouse inlet, sample set number sixteen, were selected for analysis of size-segregated particle metal content at the University of Arizona by AA/GFAA. These analyses are still in progress and the results will be reported in the next quarterly report for January through March, 1999. 


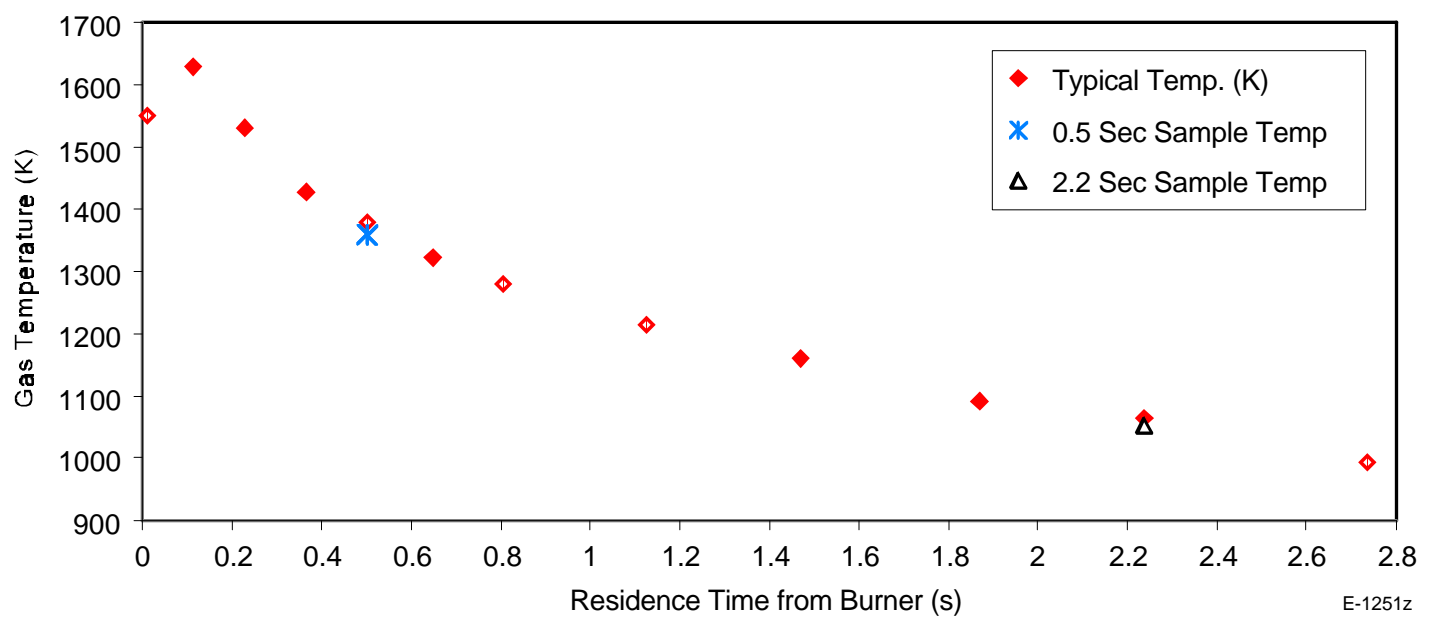

Figure 3-7. Typical naturally evolving temperature profile from Ohio baseline experiments

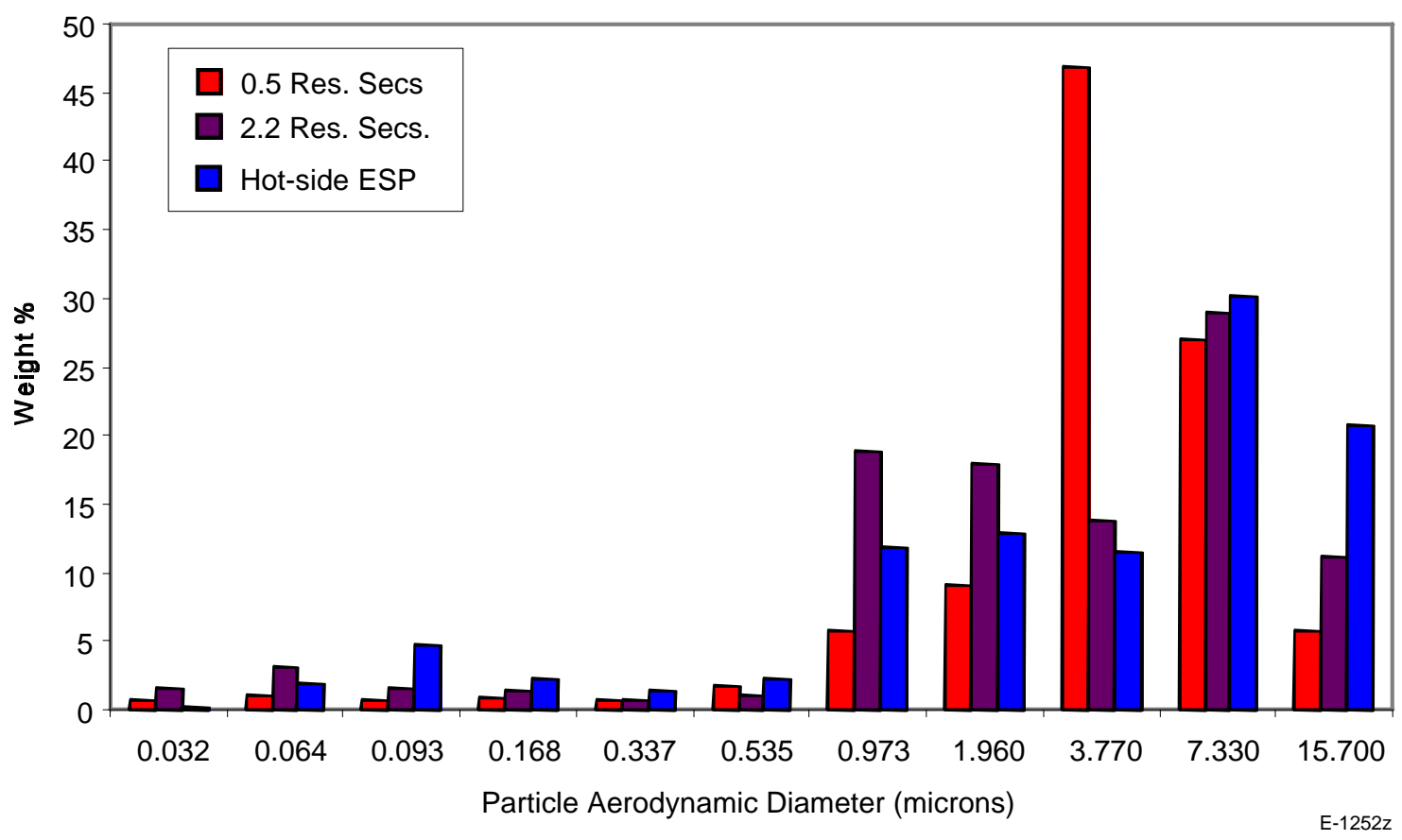

Figure 3-8. Typical particle size distributions for Ohio baseline experiments 


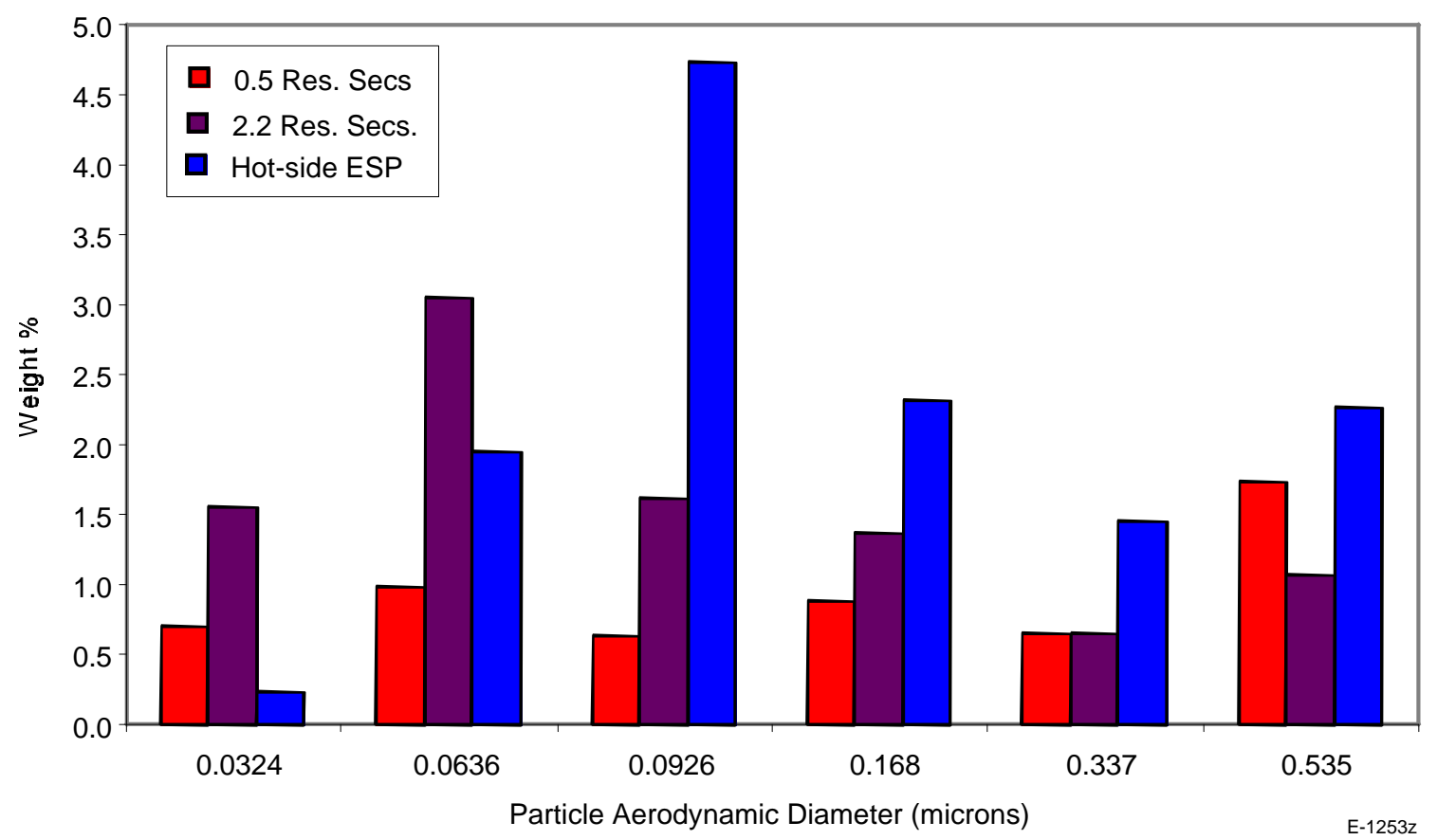

Figure 3-9. Expanded view of submicron particle size distributions for Ohio baseline experiments.

\subsubsection{Measurement of Post-Combustion Chlorine Speciation}

Measurement of chlorine speciation in post-combustion flue gas will be made at the University of Utah U-furnace using EPA Method 26A. The sample train for chlorine and $\mathrm{HCl}$ sampling has been assembled but a few parts are still missing. Work has started on designing an experimental series tentatively consisting of three conditions:

1. Exit sampling with the natural U-furnace cool-down rate (about $330 \mathrm{~K} / \mathrm{s}$ )

2. Exit sampling with a cooling coil inserted in the furnace to give faster cool-down but still within the range of practical boiler design.

3. Combustion zone sampling with a water-cooled probe giving a cool-down rate over $10^{4} \mathrm{~K} / \mathrm{S}$.

\subsubsection{Modeling of Mercury and Chlorine Kinetics}

Chlorine-containing species have been shown to be the most important for oxidation of elemental mercury in flue gas. Other flue gas constituents have relatively minor effects. Understanding the speciation of mercury in full-scale combustion systems must therefore take into consideration the kinetics of mercury and chlorine species in flue gas. As a first step, we looked at the kinetics of chlorine compounds in flue gas at realistic cooling rates. These calculations were documented in Quarterly Report \#8 (July through September, 1998). This 
quarter we began consideration of the kinetics of mercury oxidation by chlorine. The chlorine calculations will be reviewed here briefly as an introduction to the mercury calculations.

Kinetic calculations for the C-H-O-N-Cl system were carried out using the SENKIN code developed at the Sandia National Laboratories using the $\mathrm{CH}_{3} \mathrm{Cl}$ mechanism in the standard CHEMKIN-II code. The $\mathrm{CH}_{3} \mathrm{Cl}$ mechanism includes 264 elementary reactions. This code models the time evolution of a homogeneous reacting gas mixture in an open system with a constant flow rate. The initial composition was calculated according to the overall combustion reaction:

$$
\begin{aligned}
\mathrm{CH}_{0.78} \mathrm{O}_{0.13} \mathrm{Cl}_{\xi}+(1+\zeta)\left(\mathrm{O}_{2}+3.78 \mathrm{~N}_{2)}\right. & \\
& \mathrm{CO}_{2}+0.36 \mathrm{H}_{2} \mathrm{O}+(\zeta+0.05) \mathrm{O}_{2}+3.78(1+\zeta) \mathrm{N}_{2}+\xi \mathrm{Cl}
\end{aligned}
$$

where $\zeta$ is the amount of excess air relative to stoichiometric and $\xi$ is the chlorine content of the coal. The code used in this study assumes constant pressure, but allows the temperature to vary as a function of time.

The results of these calculations showed that the production of molecular chlorine falls far below equilibrium levels given the high cooling rates in power plant flue gas. This is illustrated graphically in Figure 3-10 which compares the concentration of $\mathrm{Cl}_{2}$ in the flue gas as a

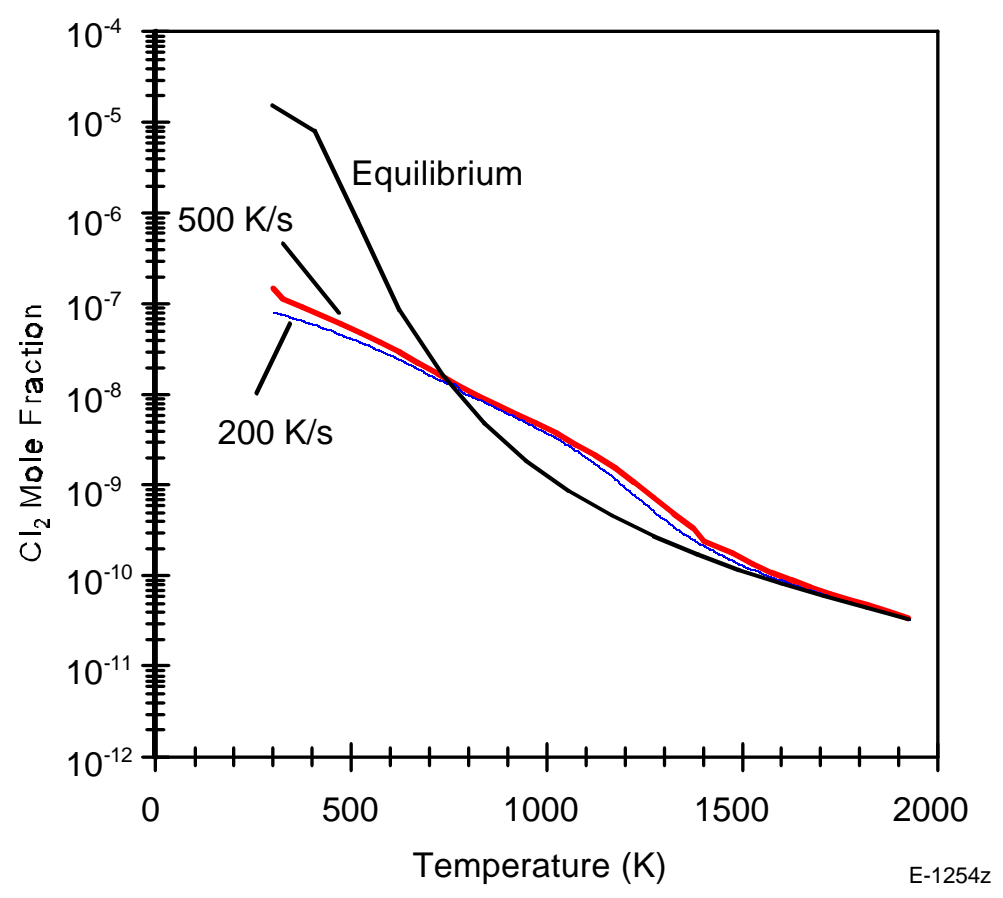

Figure 3-10. Concentration of $\mathrm{Cl}_{2}$ in flue gas as a function of temperature for different cooling rates. 
function of temperature for the case of equilibrium with kinetically-limited cases using cooling rates of $200 \mathrm{~K} / \mathrm{s}$ and $500 \mathrm{~K} / \mathrm{s}$. Between $1400 \mathrm{~K}$ and $750 \mathrm{~K}$, the concentration of $\mathrm{Cl}_{2}$ with flue gas cooling is slightly higher than the equilibrium concentration. As the temperature drops below 750 $\mathrm{K}$, the concentration of $\mathrm{Cl}_{2}$ with flue gas cooling is much lower than the equilibrium value. A more detailed examination of the kinetic mechanism shows that the three body reaction

$$
\mathrm{Cl}+\mathrm{Cl}+\mathrm{M}->\mathrm{Cl}_{2}+\mathrm{M}
$$

to be the pathway for production of $\mathrm{Cl}_{2}$. For the high cooling rates in practical combustion systems, this reaction is not fast enough at temperatures below $750 \mathrm{~K}$ to produce much molecular chlorine. The kinetic model thus predicts super-equilibrium concentrations of the chlorine radical at temperatures below $1500 \mathrm{~K}$ as shown in Figure 3-11.

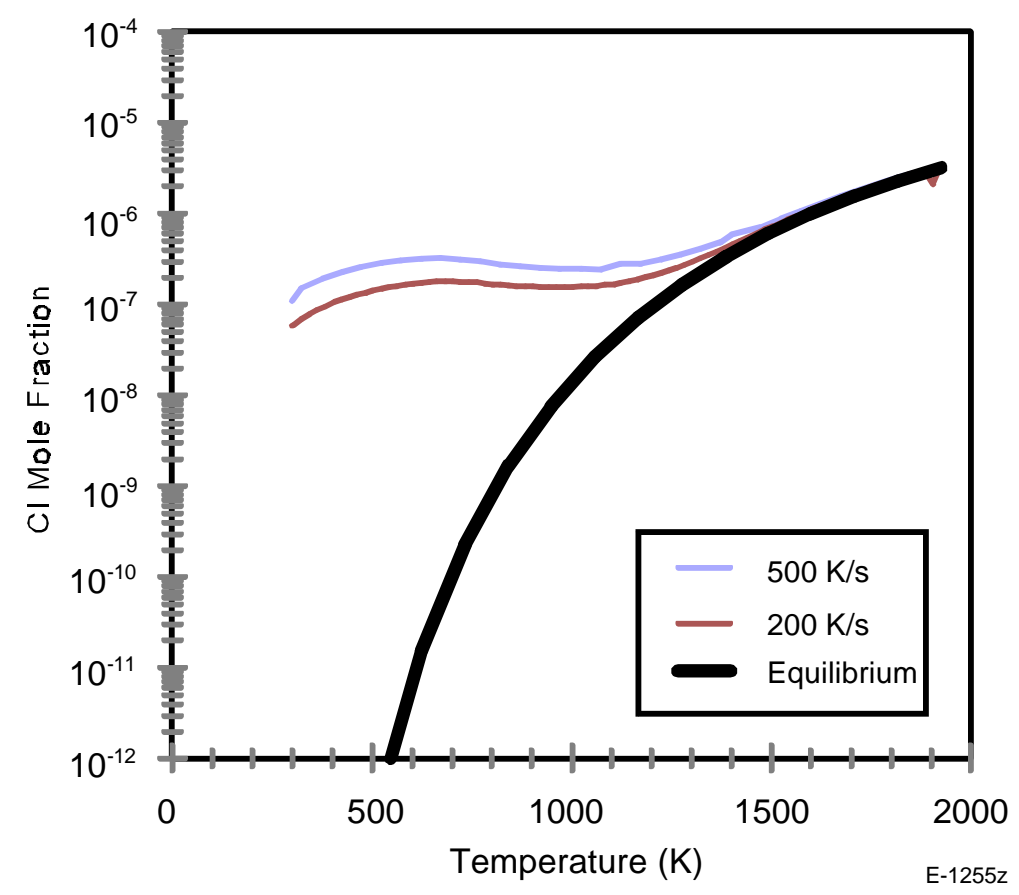

Figure 3-11. Concentration of $\mathrm{Cl}$ in flue gas as a function of temperature for different cooling rates.

To investigate the importance of reaction kinetics in determining the extent of mercury oxidation, kinetic calculations of mercury oxidation were conducted for conditions relevant to pulverized coal combustion. Two different kinetic models were considered. Global kinetics derived from the studies of Hall et al. ${ }^{5}$ and Gaspar et al. ${ }^{6}$ were used to examine overall mercury oxidation under a range of conditions. To assess the importance of atomic $\mathrm{Cl}$, further kinetic calculations were conducted using elementary reactions.

Hall et al. ${ }^{5}$ report data for total mercury and elemental mercury concentrations obtained in a flow reactor at a temperature of $500^{\circ} \mathrm{C}$ corresponding to a residence time of approximately $1.5 \mathrm{~s}$. Upstream of the sampling point, temperatures are greater than $600^{\circ} \mathrm{C},{ }^{7}$ but peak temperatures and temperature profiles are not provided by the authors. Modeling the reactor as an 
isothermal plug flow device, a rate constant of $\mathrm{k}=1.07 \mathrm{E}-15 \mathrm{~cm}^{3}$ molecule $\mathrm{s}^{-1}$ at $500^{\circ} \mathrm{C}$ for the global reaction

$$
\mathrm{Hg}+\mathrm{Cl}_{2} \rightarrow \mathrm{HgCl}_{2}
$$

is obtained. This rate constant represents a maximum possible value because of the uncertainties in gas thermal history and the likelihood that reaction occurred at temperatures greater than $500^{\circ} \mathrm{C}$. It is of comparable magnitude to the value reported by Schroeder et al. ${ }^{8}$ as $4 \times 10^{-16} \mathrm{~cm}^{3}$ molecule $\mathrm{e}^{-1} \mathrm{~s}^{-1}$ for the same reaction under ambient conditions. Using these two values of the reaction rate constant and assuming an Arrhenius-type temperature dependence, the activation energy for this reaction is estimated to be $3.7 \mathrm{~kJ} \mathrm{~mol}^{-1}$.

For the global reaction with $\mathrm{HCl}$,

$$
\mathrm{Hg}+\mathrm{HCl} \rightarrow \text { oxidized products }
$$

Gaspar et al. ${ }^{6}$ report a rate constant of $\mathrm{k}=2.20 \times 10^{7} \exp (-3460 / \mathrm{T})$ liters $\mathrm{mol}^{-1} \mathrm{~s}^{-1}$ over the temperature range 400 to $900^{\circ} \mathrm{C}$. This latter rate constant was derived from experiments conducted at $\mathrm{HCl}$ concentrations of 300 and 3000 ppmv, mercury concentrations of $0.37 \mathrm{ppmv}$ (approximately 10 to 20 times greater than typical values associated with pulverized coal combustion), and approximate residence times of 1 second.

In considering the global reactions of $\mathrm{Hg}$ with $\mathrm{Cl}_{2}$ and $\mathrm{HCl}$ (Eqs. 3 and 4), we ran both "reactions" simultaneously. The reason for doing this was that the rates were derived from studies in which only $\mathrm{Cl}_{2}$ or $\mathrm{HCl}$ was injected, and thus represent reactions derived from those species alone. Since we believe $\mathrm{Cl}$ atom is responsible at the elementary level, this choice (considering both "reactions" simultaneously) ignores interplay between $\mathrm{Cl}$ derived from $\mathrm{Cl}_{2}$ and $\mathrm{HCl}$, and could thus be considered a maximum rate of conversion.

Studies of the mechanism of mercury oxidation at temperatures of $600^{\circ} \mathrm{C}$ and above by Kramlich et al. ${ }^{9}$ suggest that the key oxidizing species is atomic $\mathrm{Cl}$. We propose a homogeneous pathway, governed by the principal steps,

$$
\begin{gathered}
\mathrm{Hg}+\mathrm{Cl}(+\mathrm{M}) \rightarrow \mathrm{HgCl}(+\mathrm{M}) \\
\mathrm{HgCl}+\mathrm{Cl} \rightarrow \mathrm{HgCl}_{2} \\
\mathrm{HgCl}+\mathrm{HCl} \rightarrow \mathrm{HgCl}_{2}
\end{gathered}
$$

Kramlich et al. note that super-equilibrium concentrations of $\mathrm{Cl}$ are required to account for observed $\mathrm{HgCl}_{2}$ concentrations.

The consumption of elementary mercury proceeds by Reaction (5). An average rate constant for this reaction, $1.5 \times 10^{13} \mathrm{~cm}^{3} \mathrm{~mol}^{-1} \mathrm{~s}^{-1}$, is derived from the data of Horne et al. ${ }^{10}$ and is equal to the value recommended by Kramlich et al. ${ }^{9}$ This value is approximately one order of 
magnitude less than the value derived from collision theory, $1.8 \times 10^{14} \mathrm{~cm}^{3} \mathrm{~mol}^{-1} \mathrm{~s}^{-1}$. The rate constant for Reaction (6) as a function of temperature was estimated from collision theory: ${ }^{11}$

$$
\mathrm{k}=\pi \delta_{\mathrm{AB}}^{2}\left(\frac{8 \mathrm{k}_{\mathrm{b}} \mathrm{T}}{\pi \mathrm{m}_{\mathrm{r}}}\right)^{0.5} \mathrm{p}
$$

where

$\mathrm{p}=1$ (steric factor, typical)

$\mathrm{k}_{\mathrm{b}}=$ Boltzman constant

$\mathrm{m}_{\mathrm{r}}=$ reduced mass

$\delta_{\mathrm{AB}}=$ Average diameter of hard spheres.

The information for the radius of each species was estimated from the National Institute of Standards and Technology (NIST) thermochemical webbook. ${ }^{12}$ Figure 3-12 gives the rate constant of Reaction (6) as a function of temperature from $273 \mathrm{~K}$ to $973 \mathrm{~K}$.

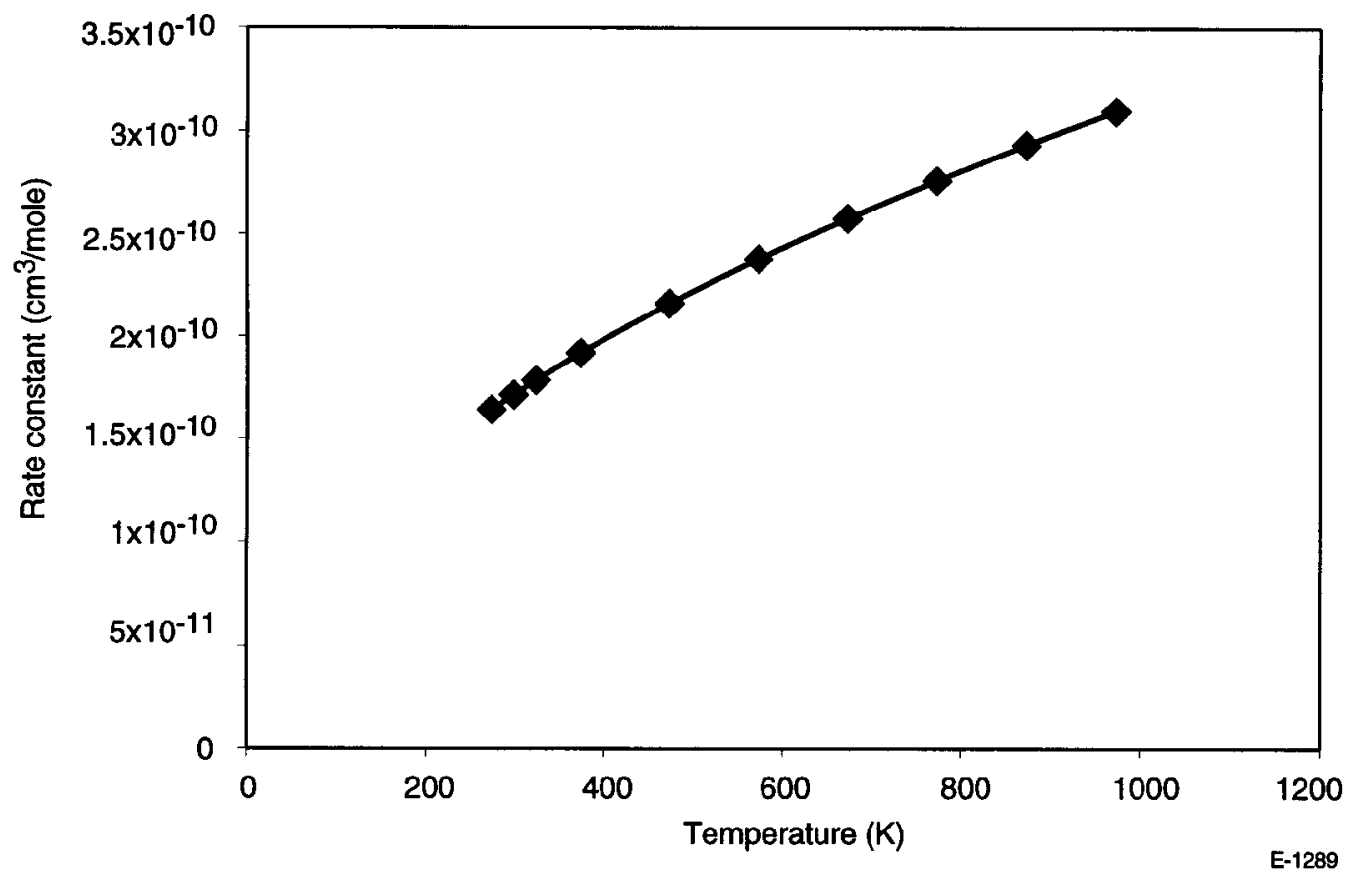

Figure 3-12. Rate constant of Reaction (6) as a function of temperature from $273 \mathrm{~K}$ to $973 \mathrm{~K}$.

The rate constant for Reaction (7) was estimated at a reference temperature (2000 K) from collision theory (Equation 8). Laidler provides empirical methods to estimate activation energies based on enthalpies of reaction. ${ }^{13}$ In order to obtain a temperature dependency, an activation energy had to be estimated using the form:

$$
\mathrm{k}=\mathrm{k}_{\mathrm{REF}} \exp (-\mathrm{E} / \mathrm{RT})
$$


where $\mathrm{k}_{\mathrm{REF}}$ in this case is estimated from collision theory at $2000 \mathrm{~K}$. Using the Polanyi-Semenov equation, for exothermic reactions:

$$
\mathrm{E}=48 \mathrm{~kJ} / \mathrm{mol}-0.25 \mathrm{Q}
$$

where $\mathrm{Q}$ is the enthalpy of reaction. For the Reaction (7), the enthalpy of reaction is estimated to be $132 \mathrm{~kJ} / \mathrm{mol}$, based on NIST data. ${ }^{12}$ Thus the activation energy, E, is calculated to be $15 \mathrm{~kJ} / \mathrm{mol}$. Therefore, the rate constant for Reaction (7) is $\mathrm{k}=2.6 \times 10^{14}$ $\exp [-15000 / \mathrm{RT}] \mathrm{cm}^{3} / \mathrm{mol}$.

We considered the reverse of Reaction (5) in the two-step elementary reaction sequence as well. The reverse rate constant was derived from the equilibrium constant using data from HSC and checked by evaluating free energy of formation values in the JANAF tables. No effect on the results was seen by including the reverse reaction. We did not consider the reverse of Reactions (6) or (7). We assumed that $\mathrm{HgCl}$ levels would not build up in the vapor phase, so that the proposed two-step reaction mechanism reacts the $\mathrm{HgCl}$ at collision-limited rates to $\mathrm{HgCl}_{2}$.

Mercury consumption rates were derived from kinetic calculations conducted using the global reaction sequence (both Reactions 3 and 4) and the mechanistic pathway (Reactions 5 through 7). Mercury concentrations of $0.15 \mathrm{ppmw}$ in the coal, corresponding to $0.01 \mathrm{ppmv}$ in the flue gas, were used. Concentrations of the oxidants $\mathrm{HCl}, \mathrm{Cl}_{2}$, and $\mathrm{Cl}$ were taken from the combustion gas kinetic calculations described above. Reactions were examined at the isothermal conditions of $773 \mathrm{~K}$ and $973 \mathrm{~K}$ as well as under cooling rates of $-200 \mathrm{~K} \mathrm{~s}^{-1}$ and $-500 \mathrm{~K} \mathrm{~s}^{-1}$, in each case starting from a peak temperature of approximately $973 \mathrm{~K}$.

In Figures 3-13 and 3-14, mercury conversion under isothermal conditions is presented as a function of $\mathrm{HCl}$ concentrations at temperatures of 773 and $973 \mathrm{~K}$, respectively. A residence time of 2 seconds was used in these calculations. Baseline $\mathrm{Cl}_{2}$ and $\mathrm{HCl}$ concentrations were those obtained from the major constituent gas phase kinetic simulation at each temperature. Using the $773 \mathrm{~K}$ baseline concentrations of $0.013 \mathrm{ppm} \mathrm{Cl}_{2}$ and $32 \mathrm{ppm} \mathrm{HCl}$, mercury conversions of approximately $25 \%$ at $773 \mathrm{~K}$ and $45 \%$ at $973 \mathrm{~K}$ are obtained. In Figures 3-15 and 3-16, mercury conversion is presented as a function of $\mathrm{Cl}_{2}$ concentration. A greater sensitivity to changes in $\mathrm{Cl}_{2}$ concentration for the global kinetic sequence is observed.

To investigate mercury oxidation under thermal profiles associated with coal combustion, calculations using the combined global reactions were also conducted at cooling rates of -200 and $-500 \mathrm{~K} \mathrm{~s}^{-1}$. Initial conditions for these calculations are presented in Table 3-6. As shown in Figure 3-17, mercury conversion is higher at the slower cooling rate, a result of increased residence time at higher temperatures. For the cooling rate of $-200 \mathrm{~K} \mathrm{~s}^{-1}$, an overall conversion of $24 \%$ is achieved in 2 seconds. At the higher cooling rate, an asymptotic value of $10.5 \%$ conversion is reached in 1 second. 


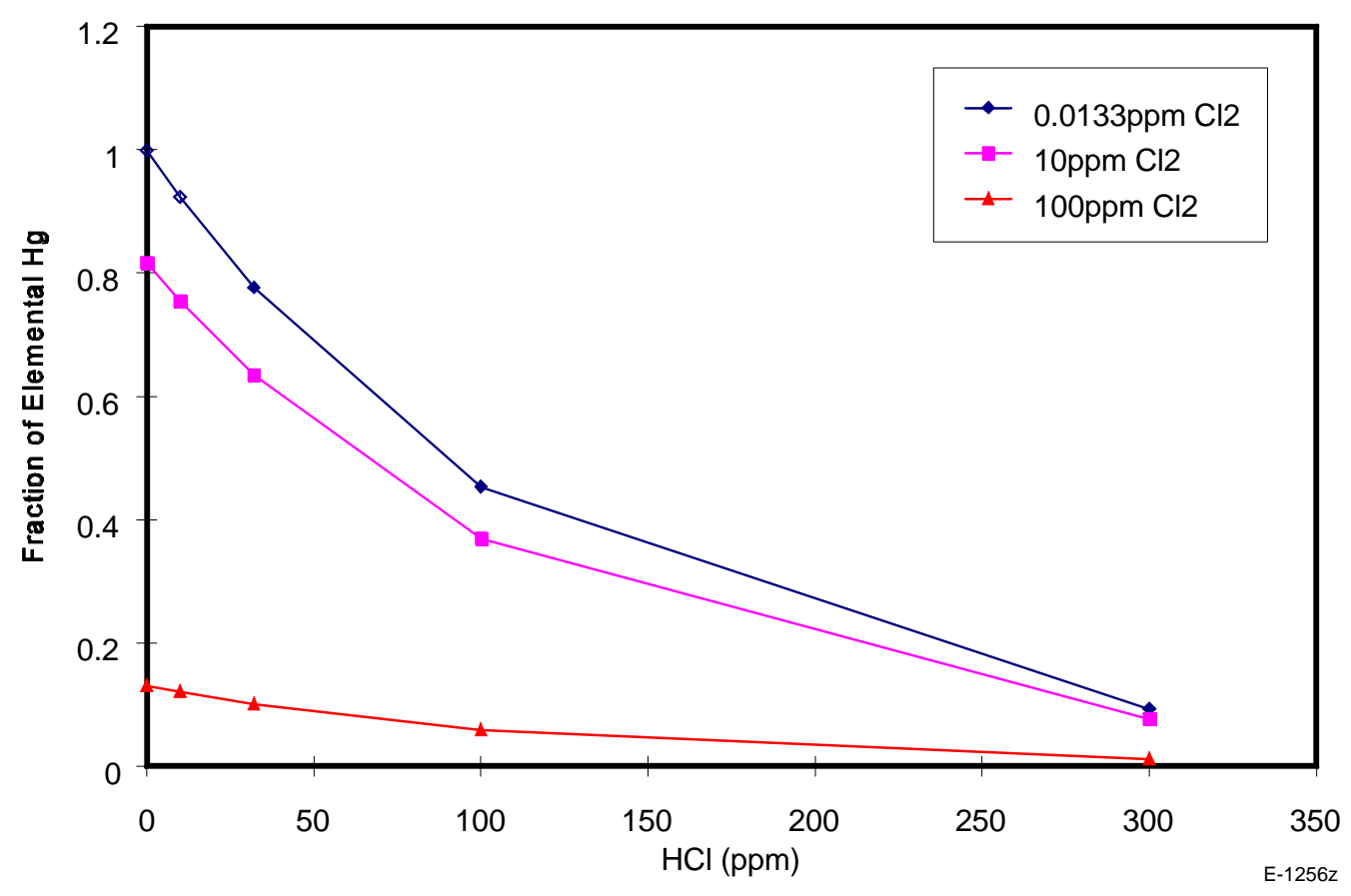

Figure 3-13. $\mathrm{Hg}$ conversion as a function of $\mathrm{HCl}$ concentration at $773 \mathrm{~K}$ using global kinetics.

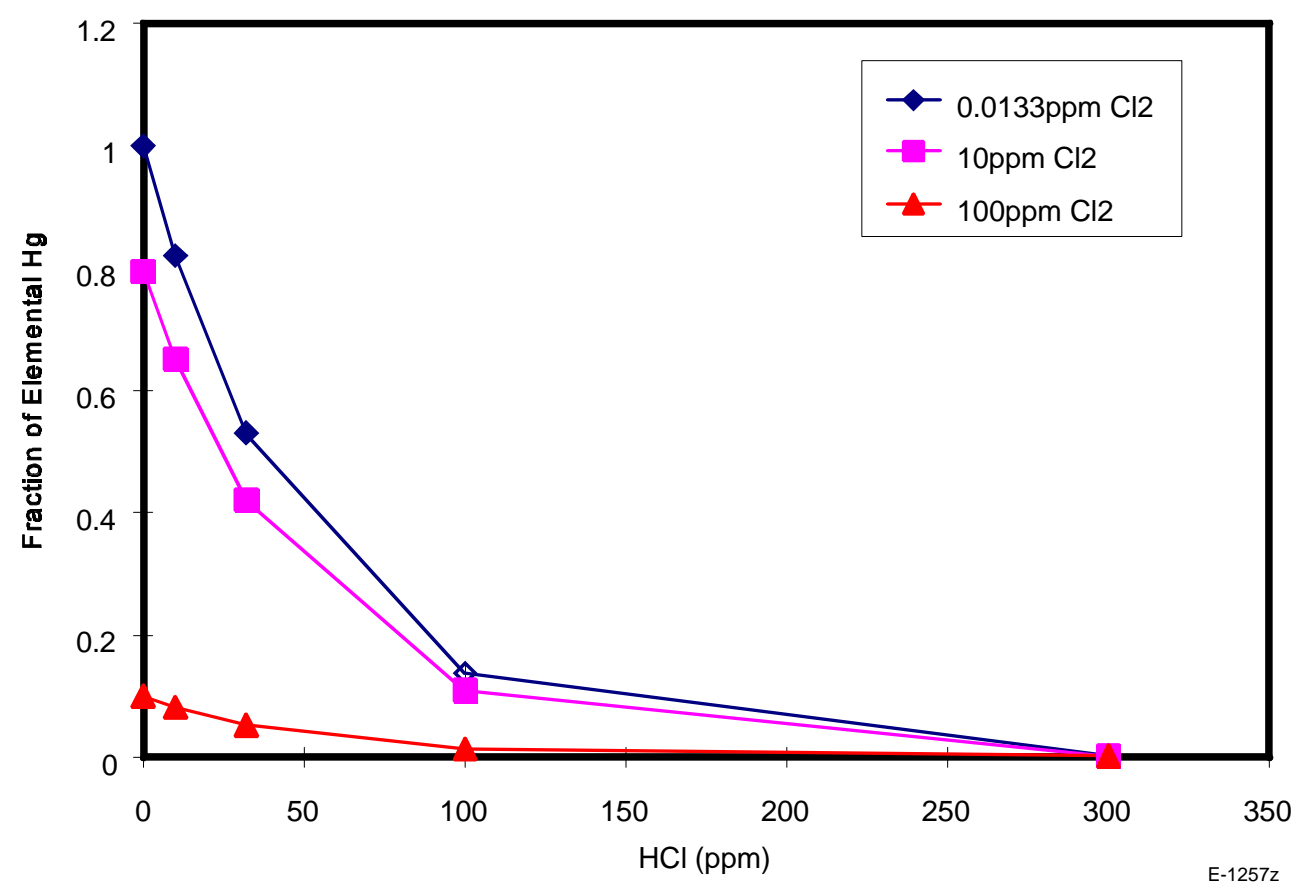

Figure 3-14. $\mathrm{Hg}$ conversion as a function of $\mathrm{HCl}$ concentration at $973 \mathrm{~K}$ using global kinetics. 


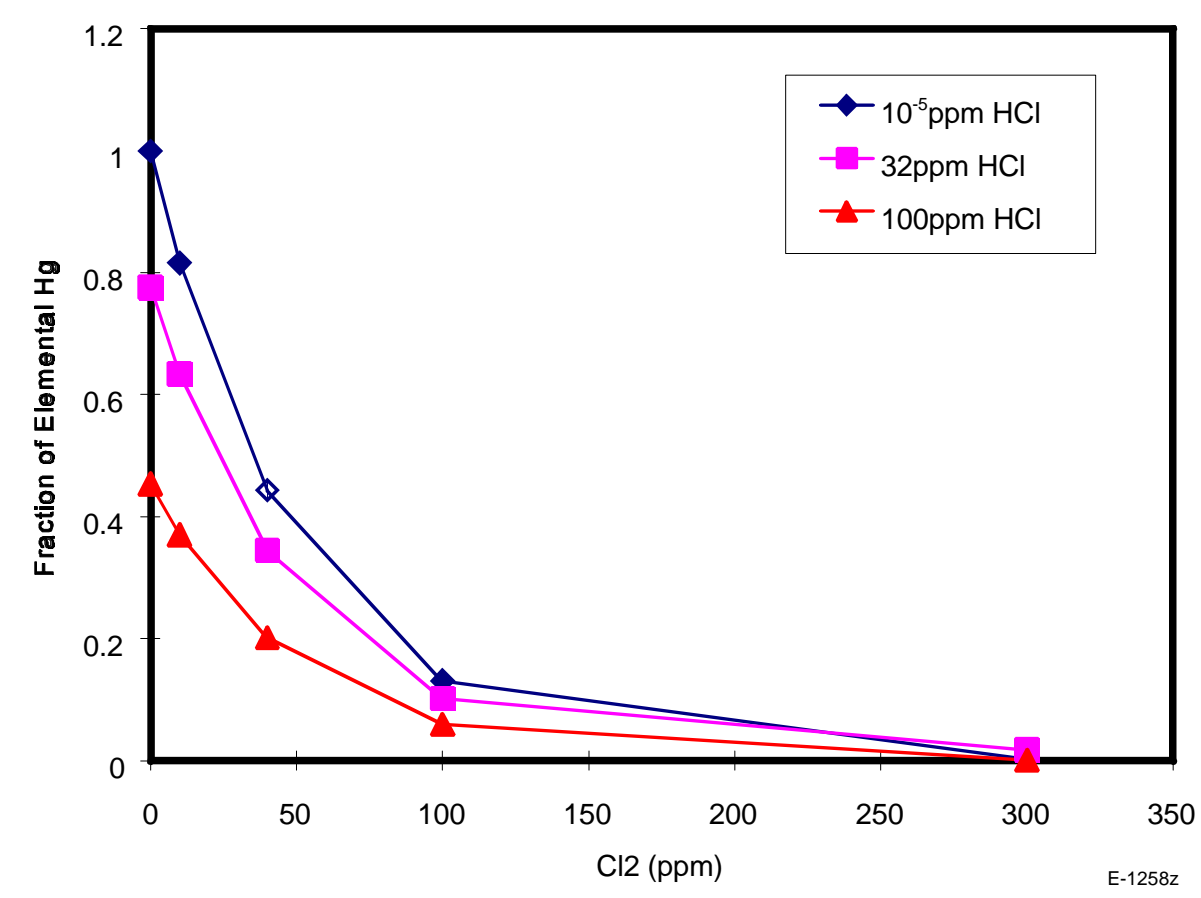

Figure 3-15. $\mathrm{Hg}$ conversion as a function of $\mathrm{Cl}_{2}$ concentration at $773 \mathrm{~K}$ using global kinetics.

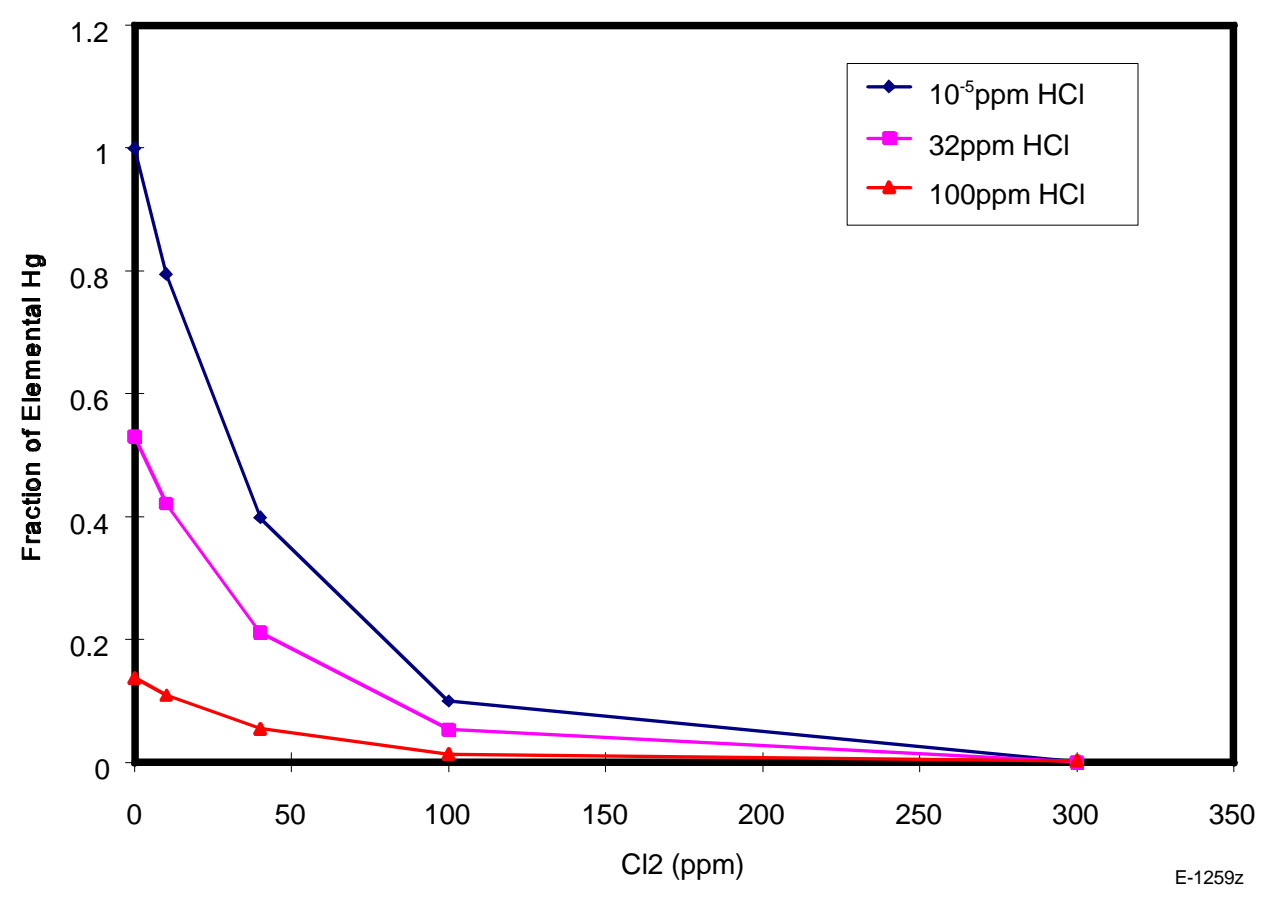

Figure 3-16. $\mathrm{Hg}$ conversion as a function of $\mathrm{Cl}_{2}$ concentration at $973 \mathrm{~K}$ using global kinetics. 
Table 3-6. Initial Conditions Used in Global Kinetic Mercury Conversion Rate Calculations

\begin{tabular}{|c|c|c|c|c|}
\hline $\mathrm{dT} / \mathrm{dt}$ & $\begin{array}{c}{[\mathrm{Hg}]} \\
(\mathrm{ppm})\end{array}$ & $\begin{array}{c}{\left[\mathrm{Cl}_{2}\right]_{\mathrm{o}}} \\
(\mathrm{ppm})\end{array}$ & $\begin{array}{c}{[\mathrm{HCl}]_{\mathrm{o}}} \\
(\mathrm{ppm})\end{array}$ & $\begin{array}{c}\mathrm{T} \text { range } \\
(\mathrm{K})\end{array}$ \\
\hline \hline$-200 \mathrm{~K} / \mathrm{s}$ & 0.01 & 0.0046 & 32 & $962.6-300$ \\
\hline$-500 \mathrm{~K} / \mathrm{s}$ & 0.01 & 0.0048 & 31.9 & $971.4-300$ \\
\hline
\end{tabular}

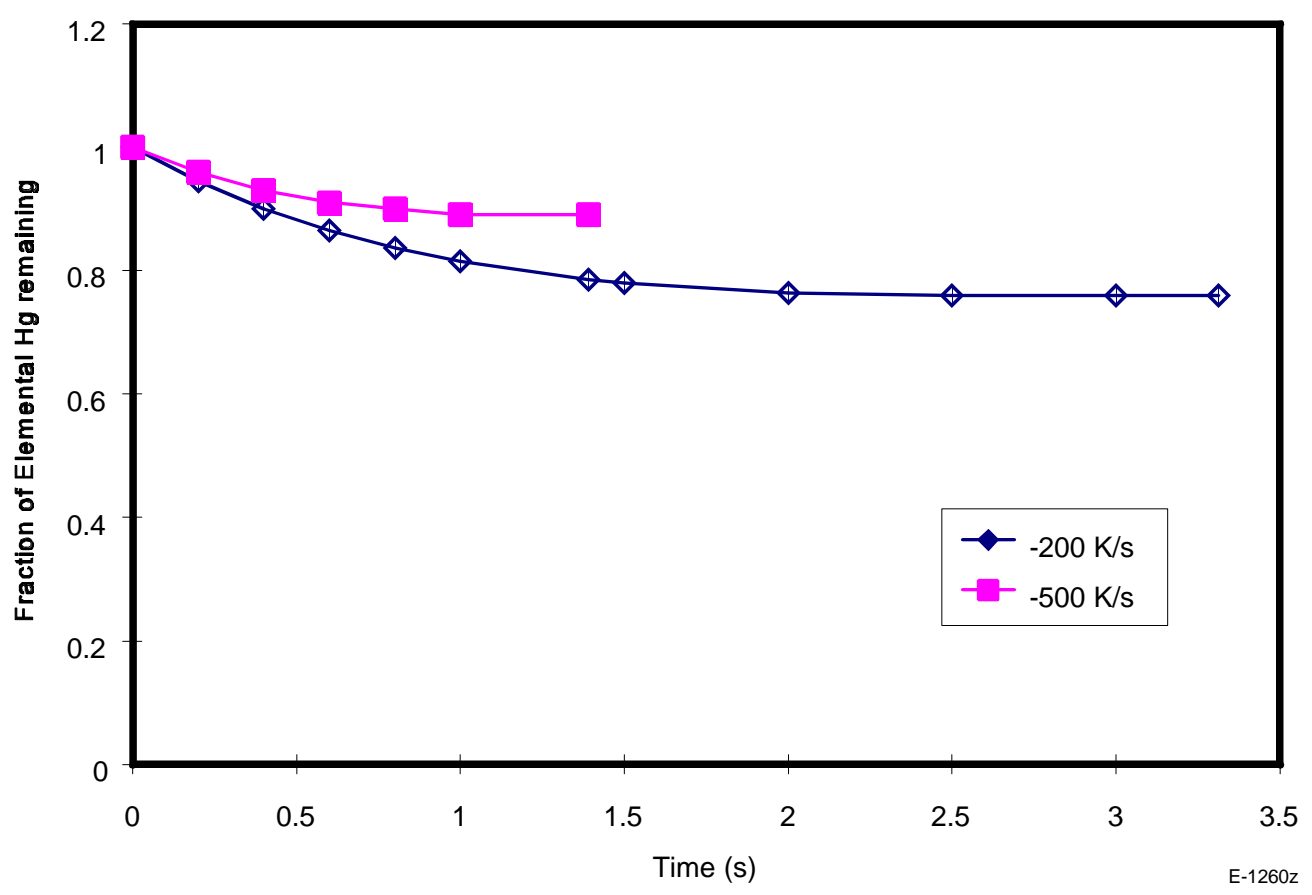

Figure 3-17. Hg conversion for two different cooling rates using global kinetics.

Mercury concentration profiles derived from the elementary reaction sequence (5)-(7) at two different cooling rates are presented in Figure 3-18. Use of this reaction set is seen to result in complete conversion of elemental mercury within $200 \mathrm{msec}$. Considering only reactions (5) and (7) still resulted in complete conversion of elemental mercury within 1 second. Order of magnitude reductions in the atomic $\mathrm{Cl}$ concentration significantly reduced the conversion, however. Figure 3-19 shows the conversion of elemental mercury at $773 \mathrm{~K}$ using reactions (5) and (7) as a function of initial atomic $\mathrm{Cl}$ concentration. Mercury conversions of comparable magnitude to the field data were obtained at atomic $\mathrm{Cl}$ concentrations of $0.00173 \mathrm{ppm}$, one hundred-fold less than those suggested by the major constituent gas phase reaction chemistry. This suggests that accurate prediction of mercury speciation in coal combustion systems using a mechanistic model will require detailed knowledge of the super-equilibrium chlorine atom concentrations. 


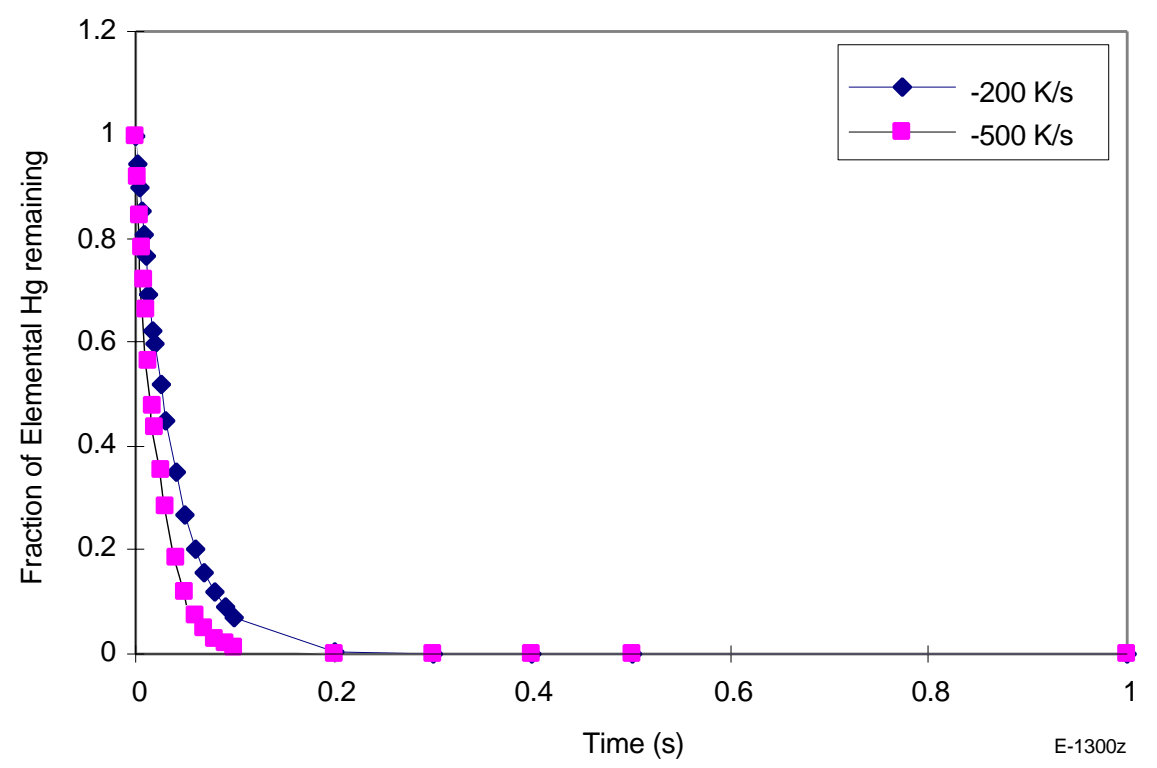

Figure 3-18. Fraction of elemental mercury converted for two different cooling rates using reactions (5)-(7).

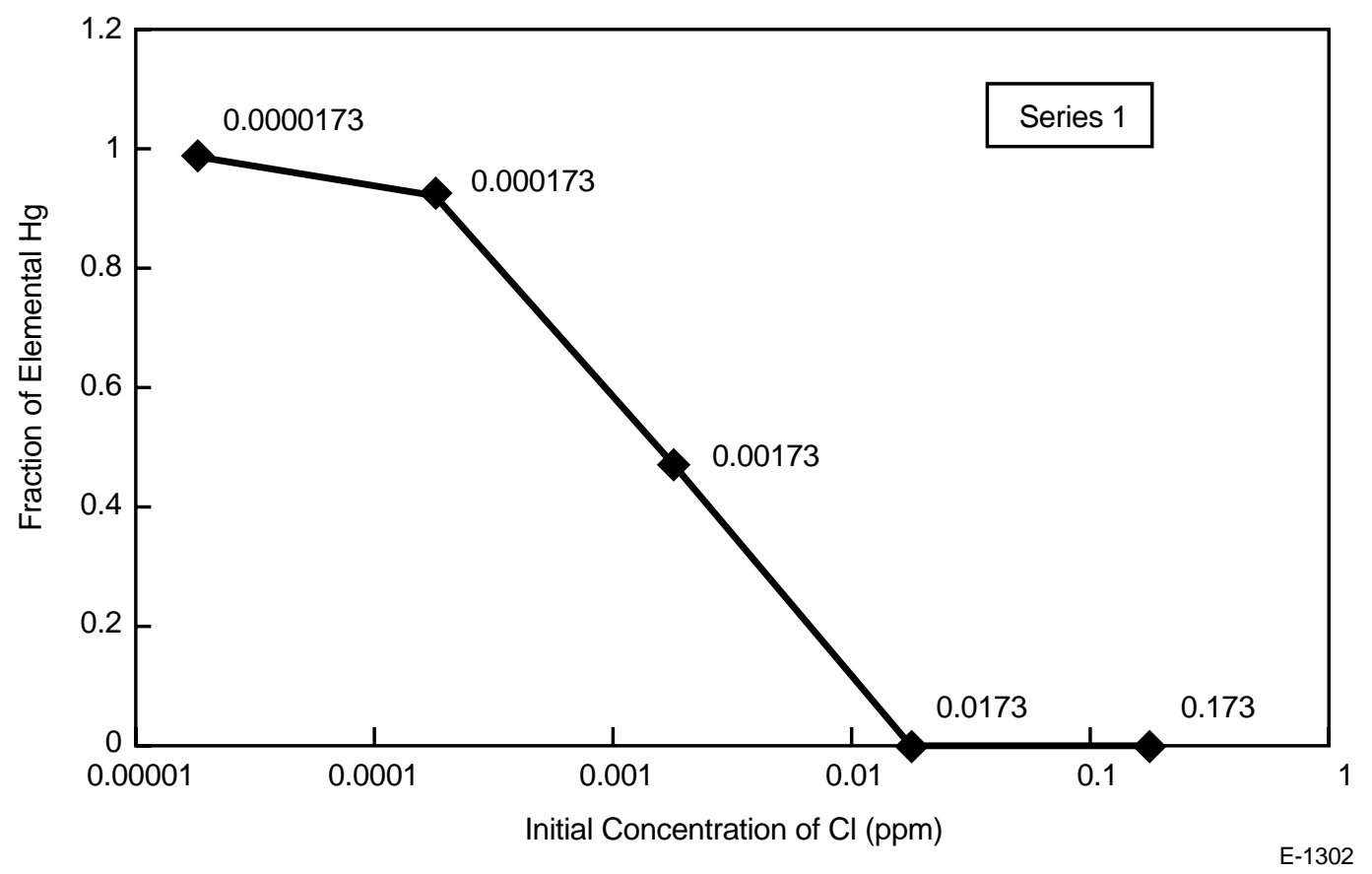

Figure 3-19. $\mathrm{Hg}$ conversion as a function of $\mathrm{Cl}$ atom concentration at $773 \mathrm{~K}$ and 1 second residence time using reactions (5) and (7). 
Chlorine-containing species have been shown to be the most important for oxidation of elemental mercury in flue gas. Other flue gas constituents (e.g., $\mathrm{H}_{2} \mathrm{O}, \mathrm{SO}_{2}, \mathrm{NO}_{2}$ ) may have secondary effects on the rate of homogeneous oxidation of mercury. We have demonstrated that the assumption of gas-phase equilibrium for mercury-containing species in coal-fired power plant exhaust is not valid at temperatures below approximately $800 \mathrm{~K}\left(500^{\circ} \mathrm{C}\right)$. The conversion of $\mathrm{HCl}$ to $\mathrm{Cl}_{2}$ in the flue gas of a coal-fired power plant is also kinetically limited. At APCD inlet temperature, equilibrium predicts as much as half of the chlorine to be in the form of $\mathrm{Cl}_{2}$, but kinetic calculations show that less than $1 \%$ of the chlorine is converted to $\mathrm{Cl}_{2}$. Kinetic calculations of the homogeneous oxidation of elemental mercury by chlorine-containing species were carried out using global reactions from the literature. The levels of mercury oxidation, while of comparable magnitude to field observations, are still below the 40 to $80 \%$ oxidation typically observed in field measurements. It is thus conceivable that heterogeneous reactions are also contributing to mercury oxidation in coal combustion systems. It must be stressed, however, that with the observed sensitivity of mercury conversion to $\mathrm{Cl}_{2}$ concentrations, and the high level of uncertainty associated with field measurements of oxidized mercury at the low concentrations of stack gases, homogeneous pathways alone may be important.

\subsubsection{XAFS Study of Mercury in Sorbents}

Data analysis of XANES spectra obtained for mercury sorbed on coal chars prepared at the University of Arizona and on similar samples prepared in other experimental projects outside of this project was discussed in detail in a previous quarterly report (April through June, 1998). ${ }^{14}$ In particular, the usefulness of the parameter derived from the mercury $\mathrm{L}_{\mathrm{III}}$-edge XANES spectra, namely the Inflection Point Difference (IPD), defined as the separation in $\mathrm{eV}$ of the peaks in the first derivative of the $\mathrm{Hg}$ XANES spectrum, was established. This parameter is a simple but effective probe of the nearest neighbor ligands that surround the mercury atoms sorbed on carbon-based sorbents. It was also noted ${ }^{14}$ that the IPD parameter for some of the char samples exhibited intermediate values between those for $\mathrm{Hg}-\mathrm{Cl}$ and $\mathrm{Hg}-\mathrm{S}$ systems.

In the current quarter, we have explored one possible reason for this variation in terms of a mixture of chemisorption, involving formation of a $\mathrm{HgCl}_{2}$ or $\mathrm{HgS}$ species on the char surface, and physisorption of elemental mercury. This was done by simulation of a suite of $\mathrm{Hg}$ XANES spectra from end-member standard spectra for metallic (liquid) mercury and either mercuric chloride or mercuric sulfide. Examples of such simulated spectra are shown in Figure 3-20 for $\mathrm{Hg}-\mathrm{HgCl}_{2}$. Also shown are the derivative spectra for the same suite of XANES spectra. It can be seen that the peak-height ratio of the derivative spectra changes systematically with the amount of $\mathrm{Hg}$ in the mixture. Hence, the combination of the IPD parameter and the derivative peak-height ratio provides a two-dimensional plot (Figure 3-21) that appears to have the potential to discriminate between chemisorption and physisorption. 


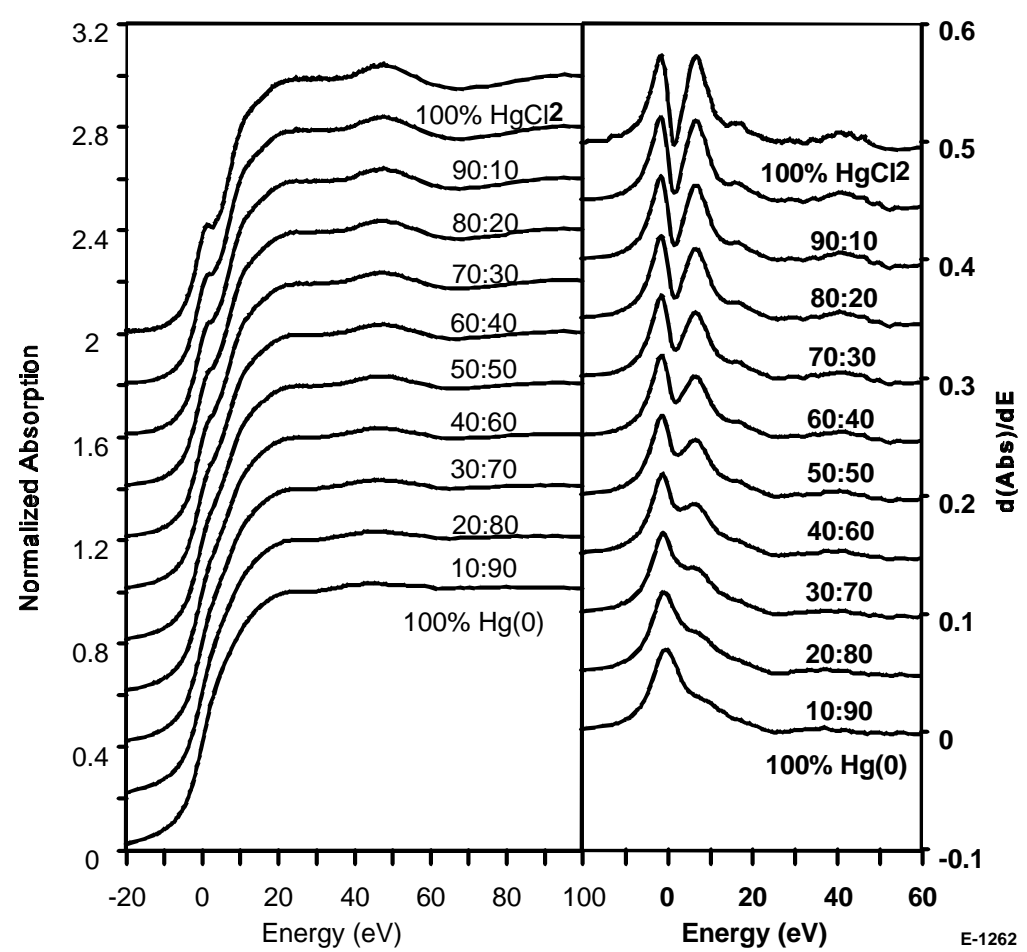

Figure 3-20. Simulated XANES spectra and derivative spectra for mercuric chloride $\left(\mathrm{HgCl}_{2}\right)$ and liquid mercury $\left(\mathrm{Hg}^{0}\right)$.

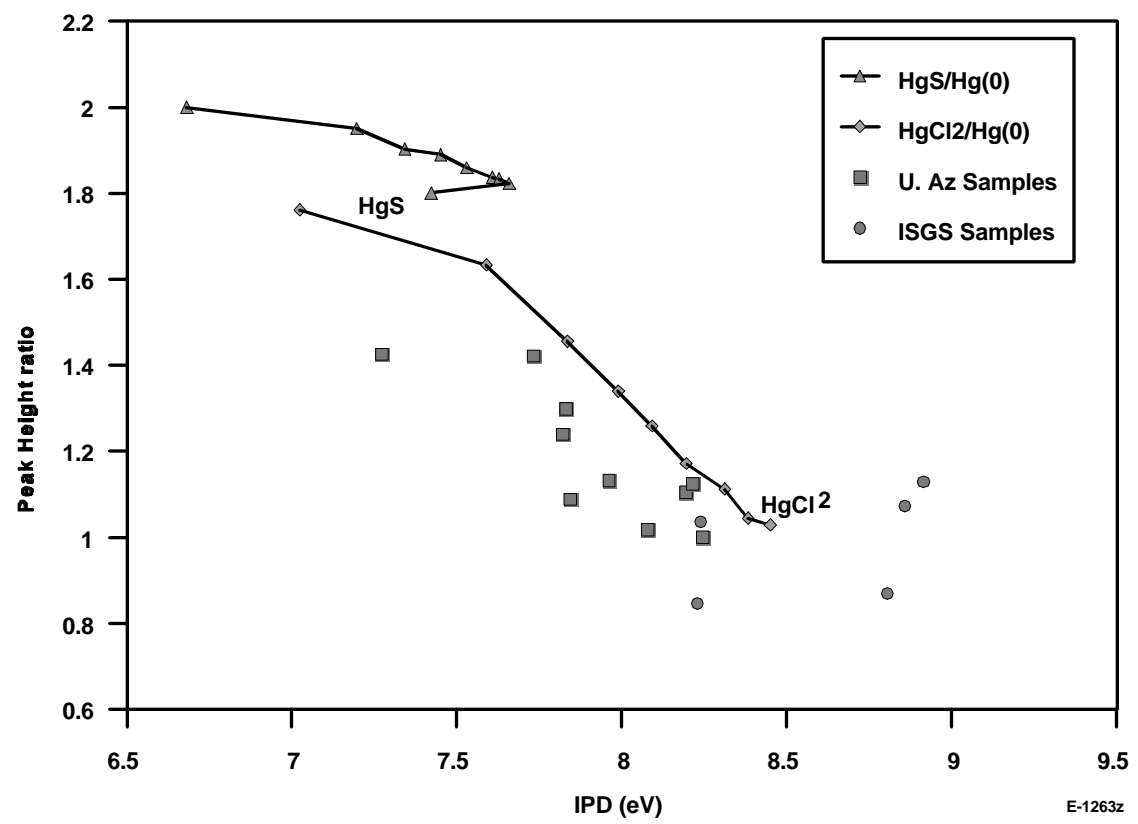

Figure 3-21. Plot of the Inflection Point Difference (IPD) against the peak-height ratio determined from the derivative spectra shown in Figure 3-20. Solid lines represent data trends from simulated mixtures of $\mathrm{Hg}^{0}$ and either $\mathrm{HgS}$ or $\mathrm{HgCl}_{2}$. Individual data points are experimental points determined for the char samples prepared at the University of Arizona or at ISGS. 
Also shown on Figure 3-21 are the Hg-XANES data obtained for the Arizona chars and it can be seen that these data are parallel but displaced relative to the IPD/Peak-height Ratio trend for $\mathrm{Hg}-\mathrm{HgCl}_{2}$. Hence, a possible explanation for the $\mathrm{Hg}$ XANES data trend shown by the Arizona char samples is that it is due to the occurrence of chemisorption of $\mathrm{Hg}$ as $\mathrm{HgCl}_{2}$ and physisorption of metallic $\mathrm{Hg}$ as competing processes. Further, the relative fraction of the chemisorption process is likely to reflect the $\mathrm{Cl} / \mathrm{Hg}$ ratio in the system, as we speculated previously. $^{14}$

Further analysis of these trends will be undertaken and new spectral data will be obtained for the standards as well as for new samples to be prepared in the course of the project. 
SECTION 4

SUMMARY AND FUTURE PLANS

4-1/4-2 


\section{SUMMARY AND FUTURE PLANS}

\subsection{Summary}

Basic coal testing at USGS is now complete. Total sulfur contents range from $0.43 \mathrm{wt} \cdot \%$ in the Wyodak to $2.68 \mathrm{wt} . \%$ in the Ohio sample. In the North Dakota and Ohio samples, about half of the total sulfur is pyritic and half is organic. The North Dakota sample also contains a minor amount of sulfate, consistent with the presence of barite in this sample. In the Wyodak sample, the majority of the sulfur is organic. Preliminary mineralogy of the three Phase II coals was determined by SEM/EDX. The Ohio coal contains all of the five most common major phases: quartz, illitic clay, kaolinitic clay, pyrite and calcite. Based on this preliminary work, the North Dakota sample appears to lack both kaolinite and calcite, and the Wyodak sample appears to lack calcite. Subsequent SEM work will attempt to reconfirm the basic findings presented here, and identify additional trace phases that could host the elements of interest in this study.

At the present time, selective leaching procedures for the Ohio and North Dakota samples have been completed, and a portion (INAA and ICP-AES acid digest) of the analytical results have been returned. The Wyodak sample was received after these two samples, and is currently in the final stage of the leaching procedure. Preliminary leaching results for the Ohio and North Dakota samples are reported, based only on INAA and CVAA $(\mathrm{Hg})$ results on the bulk starting material and the solid residues after each leaching step. Final values for percentages leached and the trace-element composition of the starting coals will be reported when all of the analyses are available. The $\mathrm{HNO}_{3}$ leaching data appears to be in error, probably due to a problem with the normality of the acid. Work will continue to re-do this step.

Electron microprobe analyses were obtained for a number of pyrite grains in each of the three Phase II coals. Elements determined include $\mathrm{Pb}, \mathrm{Se}, \mathrm{Cu}, \mathrm{Cd}, \mathrm{As}, \mathrm{Ni}, \mathrm{Zn}, \mathrm{Co}, \mathrm{Fe}$, and $\mathrm{S}$. Analytical methods are similar to those used in Phase I, except that $\mathrm{Pb}$ has been added to the procedure. The data are not sufficient to make generalizations about trace-element differences among the various forms, or to approximate average concentrations of these elements in pyrite for each sample.

Cold vapor atomic fluorescence (CVAF) development work for $\mathrm{Hg}$ analyses is ongoing at USGS. Trials indicate that the minimum detection limit by this method is limited by a total analytical blank level in the 0.01 to $0.02 \mathrm{ppm}$ (10 to $20 \mathrm{ppb}$ ) range, similar to the detection limit for the previous (CVAA) method. As an interim step, $\mathrm{Hg}$ analyses will be done by CVAA, in parallel with CVAF development. Once an acceptable CVAF blank level is attained, the analyses will be repeated as necessary.

Analysis of Se XAFS data obtained at NSLS in July 1998 for the Ohio and North Dakota coals was attempted during the quarter by the University of Kentucky. But the data were poor with relatively high noise, reflecting the fact that both coals contain only about $1.5 \mathrm{ppm}$ Se and the data collection was not long enough, especially for the North Dakota lignite. Despite the

relatively poor quality of the data, the Se XANES spectra for the Ohio coal do appear to indicate 
a significant Se/pyrite association. New Se XAFS data will be collected for all project coals during our next synchrotron session at SSRL in February 1999.

The University of Utah has begun work to determine whether metals are vaporized at the low temperatures typical of the devolatization stage of pulverized coal combustion. The heating conditions selected were those used for an ASTM volatiles determination. Duplicate samples of both the parent coal and the fixed carbon were prepared for seven coals. These samples have been sent to MIT for elemental analysis by neutron activation.

The Oxidation Drop Tube Furnace previously at MIT was transferred to the Combustion Research Laboratory of the University of Utah. The transfer process involved the design of a semi-closed cooling system as well as the reconstruction of the gas and particle feeding units and of the particle and gas collecting facilities.

MIT has re-tested its iodated charcoal sorbent traps for the collection of $\mathrm{Hg}^{0}$ and $\mathrm{HgCl}_{2}$. The $100 \mathrm{mg}$ traps were verified to be $100 \%$ efficient for total $\mathrm{Hg}$ collection at a gas flow rate of 1 liter per minute. The $\mathrm{Hg}$ blank levels in these traps is $1 \mathrm{ng}$. Therefore a reliable analysis of sampled $\mathrm{Hg}$ requires that at least a few nanograms of $\mathrm{Hg}$ be collected. This requirement for a few nanograms of collected $\mathrm{Hg}$ should be readily attainable in even the very small combustors/reactors. Progress has been made in the development of a dry system for the separate collection of $\mathrm{HgCl}_{2}$ and $\mathrm{Hg}^{0}$ which should be simpler to use than the Ontario Hydro impinger method and which will use a collection media for $\mathrm{HgCl}_{2}$ suitable for analysis by neutron activation.

The University of Arizona's pilot-scale downflow laboratory combustion furnace was used to test the partitioning of toxic metals in the Phase II baseline experiments for the Ohio coal. A total of 16 sets of particulate samples were collected during 9 test runs under baseline combustion conditions. One representative sample set from Port 4 and the corresponding sample set from Port 14 were selected for analysis of size-segregated particle metal content at MIT by NAA. Two representative sample sets from Port 4 and the corresponding sample sets from Port 14 plus one sample set from the baghouse inlet were selected for analysis of size-segregated particle metal content at the University of Arizona by AA/GFAA. These analyses are still in progress and the results will be reported in the next quarterly report.

Measurement of chlorine speciation in post-combustion flue gas will be made at the University of Utah U-furnace using EPA Method 26A. The sample train for chlorine and $\mathrm{HCl}$ sampling has been assembled but a few parts are still missing. Work has started on designing an experimental series tentatively consisting of three different gas cooling rates.

Chlorine-containing species have been shown to be the most important for oxidation of elemental mercury in flue gas. Other flue gas constituents have relatively minor effects. Understanding the speciation of mercury in full-scale combustion systems must therefore take into consideration the kinetics of mercury and chlorine species in flue gas. This quarter we began consideration of the kinetics of mercury oxidation by chlorine. To investigate the importance of reaction kinetics in determining the extent of mercury oxidation, the University of Connecticut 
conducted kinetic calculations of mercury oxidation under conditions relevant to pulverized coal combustion. Two different kinetic models were considered. Global kinetics from the literature were used to examine overall mercury oxidation under a range of conditions. Under isothermal conditions, a greater sensitivity to changes in $\mathrm{Cl}_{2}$ concentration as compared to $\mathrm{HCl}$ was observed. Calculations using the combined global reactions were also conducted at cooling rates that are typical of coal-fired power plants. Mercury conversion is higher at the slower cooling rate, a result of increased residence time at higher temperatures. For the cooling rate of $-200 \mathrm{~K} \mathrm{~s}^{-1}$, an overall conversion of $24 \%$ is achieved in 2 seconds which is consistent with measurements of gas-phase $\mathrm{Hg}^{+2}$ in coal-fired power plant flue gas.

To assess the importance of atomic $\mathrm{Cl}$, further kinetic calculations were conducted using elementary reactions. Use of this reaction set was seen to result in complete conversion of elemental mercury within 1 second. Order of magnitude reductions in the atomic $\mathrm{Cl}$ concentration significantly reduced the conversion, however. Mercury conversions of comparable magnitude to the field data were obtained at atomic $\mathrm{Cl}$ concentrations of one hundred-fold less than those suggested by the major constituent gas phase reaction chemistry. This suggests that accurate prediction of mercury speciation in coal combustion systems using a mechanistic model will require detailed knowledge of the super-equilibrium chlorine atom concentrations.

The usefulness of the parameter derived from the mercury $\mathrm{L}_{\mathrm{III}}$-edge XANES spectra, namely the Inflection Point Difference (IPD), defined as the separation in eV of the peaks in the first derivative of the $\mathrm{Hg}$ XANES spectrum, was established. This parameter is a simple but effective probe of the nearest neighbor ligands that surround the mercury atoms sorbed on carbon-based sorbents. In the current quarter, we have explored one possible reason for this variation in terms of a mixture of chemisorption, involving formation of a $\mathrm{HgCl}_{2}$ or $\mathrm{HgS}$ species on the char surface, and physisorption of elemental mercury. This was done by simulation of a suite of Hg XANES spectra from end-member standard spectra for metallic (liquid) mercury and either mercuric chloride or mercuric sulfide. The combination of the IPD parameter and the derivative peak-height ratio appears to have the potential to discriminate between chemisorption and physisorption.

\section{2 $\quad$ Future Plans}

New XAFS experimental sessions have been scheduled for 10-17 February at SSRL, Stanford University, and for 11-15 March at NSLS, Brookhaven National Laboratory. At SSRL, we will be examining elements between $\mathrm{Cr}$ and $\mathrm{Se}$, as well as the $\mathrm{L}_{\mathrm{III}}$-edge of $\mathrm{Hg}$. During the time at NSLS, both a high Z (Fe - ??) beam-line and a low Z ( $\mathrm{S}-\mathrm{Fe})$ beam-line will be available to us. We should complete the arsenic, selenium, and chromium XANES speciation of the project coals during these sessions. This work will also include XAFS examination of leached coal samples to be received from USGS prepared according to their leaching protocol. XAFS examination of these fractions prepared at USGS should be mutually beneficial for interpretation of the XANES spectra on the one hand and for understanding of the leaching chemistry on the other. 
In addition, work should be completed on the CCSEM mineralogy of the project coals; but it may be dependent on whether some minor hardware modifications are completed to the CCSEM hardware.

Low temperature ashing of the three Phase II coals is underway at USGS. Once this has been completed, Frank Dulong will do a semi-quantitative XRD procedure to determine the proportion of major mineral phases present in each coal.

Based on preliminary investigations using smaller ion microprobe facilities at NIST and the Carnegie Institution of Washington, USGS has submitted a proposal to use the newly commissioned joint USGS-Stanford University SHRIMP-RG ion microprobe at Stanford. Four specific areas of investigation were proposed, including 1) distribution of arsenic on the surface of fly ash particles, 2) distribution of mercury in sulfides in coal, 3) distribution of $\mathrm{Cr}$ in illite in coal, and 4) distribution of trace elements in coal macerals. Initial work will focus on arsenic in fly ash particles, but we hope to obtain quantitative results in each of these areas. Initial reaction from the proposal committee has been very favorable.

Combustion experiments will continue at the University of Utah and at the University of Arizona. Utah will continue analysis of the loss of trace elements during devolatilization. Work will also continue on setting up the drop tube furnace and measurement of chlorine speciation on the U-furnace by Method 26A. The University of Arizona will continue analysis of impactor samples from combustion of the Ohio coal. Work will also continue on the total filter sample to collect ash at the baghouse inlet for subsequent fixed bed tests at EERC.

The University of Connecticut will continue the chlorine kinetic calculations. In addition, set up of the flat flame burner facility for study of mercury and chlorine chemistry will commence. 
SECTION 5

REFERENCES

$5-1 / 5-2$ 


\section{REFERENCES}

1. F.E. Huggins, N. Shah, G.P. Huffman, A. Kolker, S. Crowley, C.A. Palmer, and R.B. Finkelman, "Mode of occurrence of chromium in four U.S. coals", Submitted to the Special Issue of Fuel. Proc. Technol., 1999.

2. Kolker, A., Palmer, C.A., Crowley, S.S., Finkelman, R.B., Huggins, F.E., Shaw, N., and Huffman, G.P. "Mode of Occurrence of Arsenic in Four U.S. Coals," Submitted to the Special Issue of Fuel. Proc. Technol., 1999.

3. F. E. Huggins, N. Yap, and G. P. Huffman, "XAFS Investigation of Mercury Sorption on Carbon-based and Other Sorbent Materials," Accepted for publication, Jap. J. Appl. Phys., 1999.

4. F.E. Huggins, G.P. Huffman, G.E. Dunham, and C. L. Senior, "XAFS Investigation of Mercury Sorption on Three Activated Carbons," Energy \& Fuels, 1999, 13(1), in press.

5. Hall, B., Schager, P., and Lindqvist, O. "Chemical Reactions of Mercury on Combustion Flue Gases,” Water, Air, Soil Poll. 1991, 56, 3-14.

6. Gaspar, J.A., Widmer, N.C., Cole, J.A., and Seeker, W.R. "Study of Mercury Speciation in a Simulated Municipal Waste Incinerator Flue Gas," Proceedings of 1997 International Conference on Incineration and Thermal Treatment Technologies, Oakland, CA, May 12-16, 1997.

7. Hall, B., Lindqvist, O., and Ljungstrom, E., "Mercury chemistry in simulated flue gases related to waste incineration conditions," Environ. Sci. Tech. 1990 24(1), 108-111.

8. Schroeder, W.H., Yarwood, G., and Niki, H., "Transformation processes involving mercury species in the atmosphere - results from a literature survey," Water, Air, and Soil Pollution 1991 56, 653-666.

9. Kramlich, J.C., Sliger, R.N., and Going, D.J., "Reduction of Inherent Mercury Emissions in Pulverized Coal Combustion," DOE Grant DE-FG22-95PC95216, presentation at DOE University Coal Research Contractor's Meeting, Pittsburgh, June 1997.

10. Horne, D.G., Gosavi, R., and Strausz, O.P., "Reactions of Metal Atoms I. The Combination of Mercury and Chlorine Atoms and the Dimerization of $\mathrm{HgCl}$," J. Chem. Phys. 1968 48(10), 4758-4764. 
11. Benson, S. W., The Foundations of Chemical Kinetics, McGraw-Hill: New York, NY, 1960, 271,272.

12. Laidler, K.J., Theories of Chemical Reaction Rates, McGraw-Hill: New York, NY, 1968, $38,39$.

13. NIST (National Institute of Standards and Technology). Thermochemical webbook, http://webbook.nist.gov/cgi/ .

14. C.L. Senior, T. Panagiotou, F.E. Huggins, G.P. Huffman, N. Yap, J.O.L. Wendt, W. Seames, M.R. Ames, I. Olmez, T. Zeng, A.F. Sarofim, A. Kolker, R. Finkelman, and J.J. Helble, Toxic Substances from Coal Combustion - A Comprehensive Assessment. Quarterly report No. 7, DOE Contract No. DE-AC22-95PC95101, U.S. Department of Energy, pp. 3-20 to 3-28, July 1998. 


\section{APPENDIX A}

Pyrite Analyses from SEM

A-1/A-2 
Table 1. Pyrite Phase II Samples (wt\%)

\begin{tabular}{|c|c|c|c|c|c|c|c|c|c|c|c|c|c|}
\hline No. & $\mathrm{Pb}$ & $\mathrm{Se}$ & $\mathrm{Cu}$ & $\mathrm{Cd}$ & As & $\mathrm{Ni}$ & $\mathrm{Zn}$ & Co & $\mathrm{Fe}$ & $S$ & Total & Comment & Size/Form \\
\hline 10 & 0.02 & 0.01 & 0.00 & 0.02 & 0.00 & 0.00 & 0.00 & 0.05 & 47.34 & 53.04 & 100.48 & OhioB1.1 & \multirow{2}{*}{$\begin{array}{c}30 \\
\text { Subh }\end{array}$} \\
\hline 11 & 0.00 & 0.00 & 0.00 & 0.01 & 0.00 & 0.00 & 0.00 & 0.05 & 42.22 & 52.38 & 94.65 & OhioB1.2 & \\
\hline 13 & 0.00 & 0.00 & 0.05 & 0.03 & 0.07 & 0.13 & 0.00 & 0.06 & 44.40 & 50.13 & 94.86 & OhioB3.1 & \multirow{2}{*}{$\begin{array}{c}10 \times 25 \\
\text { Subh }\end{array}$} \\
\hline 14 & 0.06 & 0.01 & 0.03 & 0.01 & 0.16 & 0.24 & 0.00 & 0.06 & 44.05 & 50.01 & 94.63 & OhioB3.2 & \\
\hline 15 & 0.00 & 0.02 & 0.00 & 0.00 & 0.00 & 0.01 & 0.00 & 0.05 & 46.99 & 52.94 & 100.01 & OhioB41 & \multirow{4}{*}{$\begin{array}{c}80 \times 80 \\
\text { Subh }\end{array}$} \\
\hline 16 & 0.00 & 0.00 & 0.00 & 0.00 & 0.07 & 0.02 & 0.00 & 0.06 & 47.08 & 51.81 & 99.04 & OhioB4.2 & \\
\hline 18 & 0.00 & 0.00 & 0.00 & 0.01 & 0.11 & 0.01 & 0.00 & 0.05 & 47.19 & 51.83 & 99.19 & OhioB4.4 & \\
\hline 19 & 0.00 & 0.00 & 0.00 & 0.01 & 0.04 & 0.01 & 0.00 & 0.06 & 47.35 & 51.88 & 99.35 & OhioB4.5 & \\
\hline 20 & 0.01 & 0.01 & 0.00 & 0.03 & 0.00 & 0.00 & 0.00 & 0.05 & 46.81 & 52.75 & 99.66 & OhioB5.1 & \multirow{4}{*}{$\begin{array}{c}90 \times 90 \\
\text { Rnd }\end{array}$} \\
\hline 21 & 0.00 & 0.01 & 0.00 & 0.02 & 0.00 & 0.00 & 0.01 & 0.04 & 46.67 & 53.32 & 100.07 & OhioB5.2 & \\
\hline 22 & 0.02 & 0.02 & 0.02 & 0.02 & 0.00 & 0.00 & 0.00 & 0.07 & 46.08 & 53.06 & 99.29 & OhioB5.3 & \\
\hline 23 & 0.10 & 0.02 & 0.02 & 0.04 & 0.00 & 0.00 & 0.00 & 0.04 & 45.82 & 51.73 & 97.76 & OhioB5.4 & \\
\hline 24 & 0.03 & 0.01 & 0.00 & 0.01 & 0.01 & 0.00 & 0.00 & 0.05 & 46.51 & 51.18 & 97.80 & OhioB6.1 & \multirow{3}{*}{$\begin{array}{c}35 \times 120 \\
\text { Subh }\end{array}$} \\
\hline 25 & 0.00 & 0.02 & 0.00 & 0.04 & 0.01 & 0.00 & 0.00 & 0.05 & 46.75 & 51.17 & 98.03 & OhioB6.2 & \\
\hline 26 & 0.00 & 0.01 & 0.01 & 0.01 & 0.02 & 0.01 & 0.00 & 0.05 & 46.49 & 52.00 & 98.60 & OhioB6.3 & \\
\hline
\end{tabular}


Table 1. Pyrite Phase II Samples (wt\%) (Continued)

\begin{tabular}{|c|c|c|c|c|c|c|c|c|c|c|c|c|c|}
\hline No. & $\mathrm{Pb}$ & $\mathrm{Se}$ & $\mathrm{Cu}$ & $\mathrm{Cd}$ & As & $\mathrm{Ni}$ & $\mathrm{Zn}$ & Co & $\mathrm{Fe}$ & $\mathrm{S}$ & Total & Comment & Size/Form \\
\hline 27 & 0.04 & 0.00 & 0.03 & 0.04 & 0.35 & 0.03 & 0.00 & 0.05 & 45.54 & 50.62 & 96.70 & OhioB7.1 & \multirow{4}{*}{$\begin{array}{c}60 \times 60 \\
\text { Rnd }\end{array}$} \\
\hline 28 & 0.04 & 0.00 & 0.01 & 0.04 & 0.01 & 0.03 & 0.01 & 0.04 & 46.22 & 50.24 & 96.65 & OhioB7.2 & \\
\hline 29 & 0.03 & 0.00 & 0.01 & 0.01 & 0.30 & 0.05 & 0.00 & 0.06 & 45.82 & 49.33 & 95.60 & OhioB7.3 & \\
\hline 30 & 0.02 & 0.00 & 0.01 & 0.00 & 0.04 & 0.05 & 0.00 & 0.06 & 46.30 & 50.30 & 96.78 & OhioB7.4 & \\
\hline 31 & 0.16 & 0.02 & 0.01 & 0.00 & 0.07 & 0.00 & 0.00 & 0.06 & 44.76 & 48.91 & 93.99 & OhioB8.1 & \multirow{3}{*}{$\begin{array}{c}80 \text { x } 90 \\
\text { Rnd }\end{array}$} \\
\hline 32 & 0.15 & 0.00 & 0.01 & 0.03 & 0.05 & 0.11 & 0.00 & 0.08 & 43.75 & 49.56 & 93.74 & OhioB8.2 & \\
\hline 33 & 0.10 & 0.01 & 0.03 & 0.03 & 0.06 & 0.01 & 0.00 & 0.06 & 44.52 & 48.71 & 93.53 & OhioB8.3 & \\
\hline 36 & 0.00 & 0.00 & 0.01 & 0.02 & 0.00 & 0.00 & 0.00 & 0.06 & 45.15 & 48.93 & 94.17 & OhioB9.2 & \multirow{2}{*}{$\begin{array}{c}60 x 90 \\
\text { Irreg }\end{array}$} \\
\hline 37 & 0.00 & 0.01 & 0.00 & 0.01 & 0.00 & 0.00 & 0.00 & 0.05 & 44.48 & 49.14 & 93.69 & OhioB9.3 & \\
\hline 39 & 0.00 & 0.00 & 0.01 & 0.00 & 0.02 & 0.00 & 0.00 & 0.05 & 47.54 & 51.80 & 99.43 & OhioB10.1 & \multirow{5}{*}{$\begin{array}{c}120 \times 170 \\
\text { Subh }\end{array}$} \\
\hline 40 & 0.00 & 0.01 & 0.04 & 0.01 & 0.04 & 0.06 & 0.00 & 0.06 & 47.07 & 51.90 & 99.17 & OhioB10.2 & \\
\hline 41 & 0.00 & 0.00 & 0.04 & 0.03 & 0.02 & 0.04 & 0.00 & 0.05 & 47.37 & 51.59 & 99.13 & OhioB10.3 & \\
\hline 42 & 0.03 & 0.00 & 0.00 & 0.00 & 0.01 & 0.00 & 0.00 & 0.06 & 47.39 & 51.41 & 98.90 & OhioB10.4 & \\
\hline 43 & 0.01 & 0.00 & 0.03 & 0.03 & 0.04 & 0.03 & 0.01 & 0.05 & 46.78 & 51.55 & 98.52 & OhioB10.5 & \\
\hline 44 & 0.00 & 0.01 & 0.03 & 0.01 & 0.04 & 0.01 & 0.00 & 0.05 & 45.44 & 49.55 & 95.14 & OhioB11.1 & \multirow{4}{*}{$\begin{array}{c}70 \times 190 \\
\text { Oval }\end{array}$} \\
\hline 45 & 0.00 & 0.02 & 0.03 & 0.03 & 0.03 & 0.00 & 0.00 & 0.05 & 45.22 & 50.02 & 95.39 & OhioB11.2 & \\
\hline 46 & 0.01 & 0.00 & 0.04 & 0.00 & 0.03 & 0.01 & 0.01 & 0.06 & 45.20 & 49.26 & 94.63 & OhioB11.3 & \\
\hline 47 & 0.00 & 0.02 & 0.03 & 0.03 & 0.04 & 0.00 & 0.00 & 0.05 & 46.13 & 50.41 & 96.70 & OhioB11.4 & \\
\hline
\end{tabular}


Table 1. Pyrite Phase II Samples (wt\%) (Continued)

\begin{tabular}{|c|c|c|c|c|c|c|c|c|c|c|c|c|c|}
\hline No. & $\mathrm{Pb}$ & $\mathrm{Se}$ & $\mathrm{Cu}$ & $\mathrm{Cd}$ & As & $\mathrm{Ni}$ & $\mathrm{Zn}$ & Co & $\mathrm{Fe}$ & $\mathrm{S}$ & Total & Comment & Size/Form \\
\hline 48 & 0.01 & 0.02 & 0.00 & 0.03 & 0.03 & 0.01 & 0.00 & 0.05 & 46.82 & 51.76 & 98.73 & OhioB11.5 & \\
\hline 49 & 0.00 & 0.00 & 0.00 & 0.01 & 0.01 & 0.00 & 0.00 & 0.06 & 46.89 & 51.24 & 98.22 & OhioB12.1 & \multirow{5}{*}{$\begin{array}{c}70 \times 120 \\
\text { Subh }\end{array}$} \\
\hline 50 & 0.00 & 0.00 & 0.00 & 0.03 & 0.02 & 0.00 & 0.00 & 0.05 & 46.79 & 51.02 & 97.90 & OhioB12.2 & \\
\hline 51 & 0.00 & 0.00 & 0.00 & 0.02 & 0.01 & 0.00 & 0.00 & 0.06 & 46.72 & 50.85 & 97.67 & OhioB12.3 & \\
\hline 52 & 0.00 & 0.00 & 0.00 & 0.02 & 0.07 & 0.06 & 0.00 & 0.06 & 46.46 & 50.93 & 97.60 & OhioB12.4 & \\
\hline 53 & 0.01 & 0.00 & 0.00 & 0.00 & 0.00 & 0.00 & 0.00 & 0.04 & 46.15 & 51.12 & 97.32 & OhioB12.5 & \\
\hline 54 & 0.04 & 0.00 & 0.01 & 0.01 & 0.11 & 0.01 & 0.00 & 0.03 & 45.97 & 50.39 & 96.58 & OhioB13.1 & \multirow{2}{*}{$\begin{array}{c}50 \times 60 \\
\text { Irreg }\end{array}$} \\
\hline 55 & 0.03 & 0.01 & 0.00 & 0.02 & 0.17 & 0.01 & 0.00 & 0.06 & 45.43 & 50.63 & 96.35 & OhioB13.2 & \\
\hline 57 & 0.00 & 0.01 & 0.02 & 0.01 & 0.08 & 0.00 & 0.00 & 0.04 & 46.63 & 52.26 & 99.06 & NDakA2.1 & \multirow{2}{*}{$\begin{array}{c}35 \text { x } 35 \\
\text { Irreg }\end{array}$} \\
\hline 59 & 0.03 & 0.01 & 0.00 & 0.02 & 0.05 & 0.00 & 0.00 & 0.05 & 46.90 & 50.69 & 97.74 & NDakA2.3 & \\
\hline 60 & 0.00 & 0.00 & 0.00 & 0.02 & 0.00 & 0.00 & 0.00 & 0.05 & 44.56 & 49.41 & 94.03 & NDakA3.1 & $\begin{array}{l}10 \times 25 \\
\text { Subh }\end{array}$ \\
\hline 62 & 0.00 & 0.00 & 0.02 & 0.02 & 0.00 & 0.15 & 0.00 & 0.06 & 46.61 & 48.75 & 95.60 & NDakA4.1 & \multirow{2}{*}{$\begin{array}{c}20 \times 25 \\
\text { Subh }\end{array}$} \\
\hline 63 & 0.02 & 0.00 & 0.00 & 0.01 & 0.00 & 0.08 & 0.00 & 0.06 & 46.58 & 52.17 & 98.92 & NDakA4.2 & \\
\hline 64 & 0.00 & 0.00 & 0.00 & 0.00 & 0.01 & 0.01 & 0.03 & 0.05 & 45.42 & 48.47 & 93.98 & NDakA5.1 & $\begin{array}{l}20 \times 20 \\
\text { Irreg }\end{array}$ \\
\hline 66 & 0.00 & 0.01 & 0.00 & 0.01 & 0.10 & 0.05 & 0.00 & 0.07 & 46.23 & 52.79 & 99.25 & NDakA6.1 & \multirow{2}{*}{$\begin{array}{c}15 \times 25 \\
\text { Subh }\end{array}$} \\
\hline 67 & 0.01 & 0.00 & 0.00 & 0.02 & 0.06 & 0.07 & 0.00 & 0.06 & 46.00 & 51.49 & 97.70 & NDakA6.2 & \\
\hline 68 & 0.05 & 0.00 & 0.00 & 0.02 & 0.00 & 0.00 & 0.00 & 0.05 & 46.29 & 50.50 & 96.92 & NDakA7.1 & $\begin{array}{l}15 \times 20 \\
\text { Subh }\end{array}$ \\
\hline
\end{tabular}


Table 1. Pyrite Phase II Samples (wt\%) (Continued)

\begin{tabular}{|c|c|c|c|c|c|c|c|c|c|c|c|c|c|}
\hline No. & $\mathrm{Pb}$ & $\mathrm{Se}$ & $\mathrm{Cu}$ & $\mathrm{Cd}$ & As & $\mathrm{Ni}$ & $\mathrm{Zn}$ & Co & $\mathrm{Fe}$ & $S$ & Total & Comment & Size/Form \\
\hline 70 & 0.00 & 0.01 & 0.00 & 0.04 & 0.07 & 0.00 & 0.00 & 0.05 & 46.91 & 52.08 & 99.15 & NDakA8.1 & \multirow{3}{*}{$\begin{array}{c}30 \times 50 \\
\text { Irreg }\end{array}$} \\
\hline 71 & 0.00 & 0.00 & 0.00 & 0.02 & 0.13 & 0.00 & 0.00 & 0.07 & 46.86 & 50.37 & 97.45 & NDakA8.2 & \\
\hline 72 & 0.00 & 0.01 & 0.01 & 0.03 & 0.14 & 0.00 & 0.00 & 0.05 & 46.41 & 51.59 & 98.25 & NDakA8.3 & \\
\hline 73 & 0.00 & 0.00 & 0.00 & 0.00 & 0.24 & 0.00 & 0.00 & 0.06 & 46.04 & 52.33 & 98.67 & NDakA9.1 & \multirow{3}{*}{$\begin{array}{l}30 \times 35 \\
\text { Subh }\end{array}$} \\
\hline 74 & 0.01 & 0.00 & 0.01 & 0.02 & 0.24 & 0.01 & 0.01 & 0.06 & 46.57 & 51.63 & 98.56 & NDakA9.2 & \\
\hline 75 & 0.00 & 0.00 & 0.00 & 0.02 & 0.24 & 0.00 & 0.00 & 0.05 & 46.34 & 51.82 & 98.47 & NDakA9.3 & \\
\hline 81 & 0.00 & 0.00 & 0.00 & 0.05 & 0.00 & 0.09 & 0.00 & 0.06 & 46.29 & 50.37 & 96.86 & NDak11.1 & \multirow{2}{*}{$\begin{array}{c}60 \times 70 \\
\text { Irreg }\end{array}$} \\
\hline 83 & 0.00 & 0.01 & 0.00 & 0.01 & 0.00 & 0.11 & 0.00 & 0.06 & 45.64 & 51.06 & 96.89 & NDak11.3 & \\
\hline 84 & 0.01 & 0.01 & 0.01 & 0.02 & 0.14 & 0.00 & 0.00 & 0.06 & 46.28 & 49.01 & 95.53 & NDak12.1 & $\begin{array}{c}15 \\
\text { Framb }\end{array}$ \\
\hline 86 & 0.01 & 0.00 & 0.00 & 0.01 & 0.03 & 0.00 & 0.00 & 0.05 & 45.81 & 52.16 & 98.08 & NDak13.2 & \multirow{2}{*}{$\begin{array}{c}35 \times 40 \\
\text { Irreg }\end{array}$} \\
\hline 87 & 0.04 & 0.01 & 0.02 & 0.02 & 0.00 & 0.00 & 0.00 & 0.06 & 46.15 & 50.17 & 96.45 & NDak13.3 & \\
\hline 88 & 0.06 & 0.04 & 0.17 & 0.04 & 0.15 & 0.07 & 0.01 & 0.06 & 45.26 & 50.21 & 96.06 & WdakB1.1 & \multirow{3}{*}{$\begin{array}{c}30 \times 40 \\
\text { Framb } \\
\text { Cluster }\end{array}$} \\
\hline 89 & 0.07 & 0.02 & 0.14 & 0.03 & 0.21 & 0.09 & 0.00 & 0.07 & 44.61 & 49.93 & 95.17 & WdakB1.2 & \\
\hline 90 & 0.07 & 0.06 & 0.17 & 0.02 & 0.18 & 0.09 & 0.00 & 0.07 & 44.17 & 50.70 & 95.52 & WdakB1.3 & \\
\hline 92 & 0.00 & 0.01 & 0.00 & 0.01 & 0.00 & 0.00 & 0.00 & 0.07 & 47.68 & 52.88 & 100.65 & Wdak2.1 & \multirow{2}{*}{$\begin{array}{c}30 \times 30 \\
\text { Subh }\end{array}$} \\
\hline 94 & 0.00 & 0.00 & 0.01 & 0.02 & 0.01 & 0.00 & 0.01 & 0.07 & 48.04 & 52.63 & 100.78 & Wdak2.3 & \\
\hline 95 & 0.01 & 0.00 & 0.00 & 0.04 & 0.01 & 0.00 & 0.00 & 0.06 & 47.41 & 52.87 & 100.39 & Wdak3.1 & \multirow{2}{*}{$\begin{array}{c}15 \times 25 \\
\text { Subh }\end{array}$} \\
\hline 96 & 0.03 & 0.00 & 0.00 & 0.03 & 0.01 & 0.00 & 0.00 & 0.06 & 48.10 & 52.58 & 100.81 & Wdak3.2 & \\
\hline
\end{tabular}


Table 1. Pyrite Phase II Samples (wt\%) (Continued)

\begin{tabular}{|c|c|c|c|c|c|c|c|c|c|c|c|c|c|}
\hline No. & $\mathrm{Pb}$ & $\mathrm{Se}$ & $\mathrm{Cu}$ & $\mathrm{Cd}$ & As & $\mathrm{Ni}$ & $\mathrm{Zn}$ & Co & $\mathrm{Fe}$ & $\mathrm{S}$ & Total & Comment & Size/Form \\
\hline 97 & 0.04 & 0.00 & 0.00 & 0.03 & 0.00 & 0.00 & 0.00 & 0.06 & 46.32 & 51.71 & 98.15 & Wdak4.1 & \multirow{6}{*}{$\begin{array}{c}60 \times 80 \\
\text { Subh }\end{array}$} \\
\hline 98 & 0.00 & 0.01 & 0.01 & 0.02 & 0.00 & 0.00 & 0.00 & 0.05 & 46.36 & 51.28 & 97.73 & Wdak4.2 & \\
\hline 99 & 0.02 & 0.00 & 0.00 & 0.03 & 0.00 & 0.00 & 0.00 & 0.05 & 46.42 & 51.20 & 97.72 & Wdak4.3 & \\
\hline 100 & 0.00 & 0.01 & 0.00 & 0.03 & 0.00 & 0.00 & 0.00 & 0.05 & 46.30 & 51.45 & 97.84 & Wdak4.4 & \\
\hline 101 & 0.00 & 0.02 & 0.00 & 0.02 & 0.00 & 0.00 & 0.00 & 0.07 & 45.50 & 51.99 & 97.60 & Wdak4.5 & \\
\hline 102 & 0.02 & 0.00 & 0.01 & 0.02 & 0.00 & 0.00 & 0.00 & 0.06 & 45.21 & 51.16 & 96.46 & Wdak4.6 & \\
\hline 104 & 0.00 & 0.00 & 0.00 & 0.03 & 0.00 & 0.00 & 0.00 & 0.07 & 45.91 & 51.43 & 97.43 & Wdak5.2 & $\begin{array}{l}40 \times 50 \\
\text { Irreg }\end{array}$ \\
\hline 106 & 0.00 & 0.06 & 0.03 & 0.04 & 0.15 & 0.09 & 0.00 & 0.06 & 44.32 & 49.15 & 93.89 & Wdak6.1 & $\begin{array}{c}20 \times 25 \\
\text { Subh }\end{array}$ \\
\hline 108 & 0.01 & 0.03 & 0.00 & 0.01 & 0.00 & 0.00 & 0.00 & 0.04 & 47.01 & 53.85 & 100.95 & Wdak7.1 & $15 \times 25$ \\
\hline 109 & 0.00 & 0.00 & 0.01 & 0.04 & 0.00 & 0.00 & 0.00 & 0.06 & 45.95 & 53.65 & 99.70 & Wdak7.2 & Sub \\
\hline
\end{tabular}

Cobalt detection limit $0.05+0.02$ wt. $\%$; detection limit for other elements $0.01 \mathrm{wt} . \%$

Pyrite Forms: Subh $=$ subhedral; Framb.$=$ framboidal; Irreg. $=$ irregular

Sizes are in micrometers 